\title{
Multifunctional Nanostructured Co-doped ZnO: The Co Spatial Distribution and the Correlated Magnetic Properties
}

\author{
Rafael T. da Silva, Alexandre Mesquita, ${ }^{b}$ Angela O. de Zevallos, ${ }^{a, c}$ Thalita Chiaramonte, ${ }^{d}$ \\ Xavier Gratens, ${ }^{e}$ Valmir A. Chitta, ${ }^{e}$ Juliana M. Morbec, fa Gul Rahman,g Victor M. García-Suárez, \\ Antonio C. Doriguetto, ${ }^{c}$ Maria I. B. Bernardi, ${ }^{i}$ Hugo. B. de Carvalho *
}

\footnotetext{
${ }^{a}$ Instituto de Ciências Exatas, Universidade Federal de Alfenas - UNIFAL-MG, 37133-840 Alfenas, MG, Brazil.

${ }^{b}$ Departamento de Física, Instituto de Geociências e Ciências Exatas, Universidade Estadual Paulista UNESP, 13500-900 Rio Claro, SP, Brazil.

${ }^{c}$ Instituto de Química, Universidade Federal de Alfenas - UNIFAL-MG, 37133-840 Alfenas, MG, Brazil.

${ }^{d}$ Departamento de Ciências Naturais, Universidade Federal de São João Del-Rei - UFSJ, 36301-160 São João Del-Rei, MG, Brazil.

${ }^{e}$ Instituto de Física da Universidade de São Paulo, 05508-090 São Paulo, SP, Brazil

${ }^{f}$ Faculty of Physics, University of Duisburg-Essen, Duisburg 47057, Germany

g Department of Physics, Quaid-i-Azam University, Islamabad 45320, Pakistan

${ }^{h}$ Departamento de Física, Universidad de Oviedo, 33007 Oviedo and Nanomaterials and Nanotechnology Research Center - CINN, Spain.

${ }^{i}$ Instituto de Física de São Carlos, Universidade de São Paulo - USP, 13560-970 São Carlos, SP, Brazil.
}

KEYWORDS: nanocrystal growth, nanocrystal doping, structural properties and magnetic properties.

\begin{abstract}
In this report we present a systematic structural and magnetic analysis of Co-doped $\mathrm{ZnO}$ nanoparticles prepared via microwave-assisted hydrothermal route. The structural data confirm the incorporation of the Co ions into the wurtzite $\mathrm{ZnO}$ lattice and a Co concentration mainly near/at the surface of the nanoparticles. This Co spatial distribution is set to passivate the surface of the $\mathrm{ZnO}$ nanoparticles, inhibiting the nanoparticle growth and suppressing the observation of a ferromagnetic phase. Based on experimental and theoretical results we propose a kinetic-thermodynamic model for the processes of nucleation and growth of the Co-doped $\mathrm{ZnO}$ nanoparticles, and attribute the observed ferromagnetic order to a ferromagnetism associated to specific defects and adsorbed elements at the surface of the nanoparticle. Our findings give valuable contribution to the understanding of both the doping process at nanoscale and the nature of the magnetic properties of the Co-doped $\mathrm{ZnO}$ system.
\end{abstract}

\section{INTRODUCTION}

The challenge of developing a new material technology to solve increasingly serious problems on global scale, pertaining to the environment, energy, and resources, is being pursued actively. It is 
against such a backdrop that $\mathrm{ZnO}$, which is a nontoxic abundant resource with a superior environmental affinity, is drawing much attention. Nanostructured $\mathrm{ZnO}$ has been extensively investigated for its versatile physical and electrochemical properties, giving it a multifunctional performance across multiple applications. With a wide bandgap (3.4 eV) and a strong binding energy ( $\sim 60 \mathrm{meV})$ at room temperature, ${ }^{1} \mathrm{ZnO}$ has been considered as an excellent material for UV lasers, ${ }^{2}$ transparent conductive oxides (TCOs), ${ }^{3}$ for application in catalysis, ${ }^{4}$ and also for dyesensitized solar cells. ${ }^{5}$ The existence of various $1 \mathrm{D}$ and $2 \mathrm{D}$ forms of $\mathrm{ZnO}$ has provided also further opportunity for its use in energy harvesting, ${ }^{6}$ including photovoltaic ${ }^{7}$ and sensor applications. ${ }^{8}$

Specifically, magnetic nanostructured $\mathrm{ZnO}$ has been also considered for biomedical applications due to its low-toxicity as bioimaging, drug delivery ${ }^{9}$ and antibacterial activity. ${ }^{10}$ The desired magnetic properties can be achieved by doping the $\mathrm{ZnO}$ matrix with magnetic elements or by incorporating magnetic complexes. As prepared, the magnetic nanostructured $\mathrm{ZnO}$ would be functionalized as both fluorescent and magnetic probe. Here, the main problem concerns the fact that usually the doping of the nanostructured $\mathrm{ZnO}$ with magnetic elements, such as $\mathrm{Fe}, \mathrm{Co}$, $\mathrm{Ni}$, and $\mathrm{Mn}$, for reasons we will show you further in this article, quenches the $\mathrm{ZnO}$ visible fluorescence that mainly arises from its surface defects. ${ }^{11-13}$ Besides, magnetic $\mathrm{ZnO}$ is also emerging as a promising dilute magnetic semiconductor (DMS) to be used as spin injection layer into spintronic semiconductor systems. Spintronics is currently attracting considerable attention because of its enormous potential in next-generation data storage and logic devices. ${ }^{14}$ According to Dietl et al., ${ }^{15}$ Mn-doped $\mathrm{ZnO}$ and GaN, wide band gap semiconductors, theoretically would present Curie temperature $\left(T_{\mathrm{C}}\right)$ above room temperature. However, the obtained results, especially for the TMdoped semiconductor oxides, regarding the nature of the often observed room temperature ferromagnetism (RTFM), are very controversial and inconclusive. Today there is a consensus that the TM-doping is not a sufficient condition to achieve the RTFM ${ }^{16,17}$ and that point defects play an important role to reach a ferromagnetic order. ${ }^{18-23}$ At nanoscale, confinement of the dopants enhances their interactions with carriers and/or spins. ${ }^{24}$ leading also to interesting properties like spin filtering. ${ }^{25}$

Concerning the doping process at nanoscale, as pointed above, the use of intentional impurities, or dopants, to control the properties of materials is essential for many technologies. However, it is a 
well-known fact that the incorporation of dopant at nanoscale is a very difficult task, ${ }^{26}$ even for highly soluble dopants, the incorporation of a significant amount of dopant atoms during synthesis is not straightforward. Even when dopants are incorporated, their concentration is typically an order of magnitude less than in the growth solution. ${ }^{27}$ These results have led to theoretical efforts to understand the mechanisms that control the doping process.

In this context, the aim of the present report is to give further contribution in the understanding of the dopant incorporation process at nanoscale and how it can affect some important properties of the materials, such as their magnetic behavior. Here nanostructured $\mathrm{Co}$-doped $\mathrm{ZnO}\left(\mathrm{Zn}_{1-x} \mathrm{Co}_{x} \mathrm{O}\right)$ samples were synthesized using a microwave-assisted hydrothermal method with Co concentration up to 7 at.\%. Among the TM elements used to dope $\mathrm{ZnO}$, Co ions in principle can be easily incorporated into the wurtzite $\mathrm{ZnO}(w$ - $\mathrm{ZnO})$ lattice, once it can assume the +2 oxidation state and a crystal radius quite close to that of the $\mathrm{Zn}^{2+}$. Considering the magnetic properties, Co has one of the highest magnetic moments $\left(4.8 \mu_{\mathrm{B}}\right)$ and a positive magnetic exchange coupling constant in the metallic phase. This synthesis method combines the advantages of both hydrothermal and microwave-irradiation techniques, such as very short reaction times and the production of small particles with a narrow size distribution. ${ }^{28}$ We performed a detailed structural analysis by conjugating several different techniques to fully characterize the structures of the samples. The relationships between the magnetic properties and the structure results of the nanostructured Co-doped $\mathrm{ZnO}\left(\mathrm{Zn}_{1-}\right.$ ${ }_{x} \mathrm{Co}_{x} \mathrm{O}$ ) samples are presented. First-principles calculations were also performed to gain insight into the mechanisms of the $\mathrm{Co}$ incorporation in the $\mathrm{ZnO}$ nanocrystals and the observed magnetic properties.

\section{EXPERIMENTAL METHODS}

Nanostructured Co-doped $\mathrm{ZnO}\left(\mathrm{Zn}_{1-x} \mathrm{Co}_{x} \mathrm{O}\right)$ samples were synthesized via microwave-assisted hydrothermal route with Co nominal concentrations ( $\left.x_{\mathrm{N}}\right)$ of 0 (Undoped), $0.5,1,3,5$ and 7 at.\% $\left(x_{\mathrm{N}}=\right.$ 0, 0.005, 0.01, 0.03, 0.05 and 0.07). In a typical procedure to obtain the $\mathrm{Zn}_{1-x} \mathrm{Co}_{x} \mathrm{O}$ nanostructures, $0.02 \mathrm{~mol}$ of $\mathrm{ZnCl}_{2}$ and $\mathrm{CoCl}_{2}$, keeping the desired stoichiometric proportion between the cations, were dissolved in $50 \mathrm{~mL}$ of distilled water. Then, $50 \mathrm{ml}$ of $10 \mathrm{~mol} \mathrm{~L}^{-1} \mathrm{NaOH}$ solution was added rapidly under vigorous stirring. The mixed solution was placed in a $110 \mathrm{~mL}$ Teflon autoclave reaching $90 \%$ of its volume, which was sealed and placed in a microwave hydrothermal system, 
applying $2.45 \mathrm{GHz}$ of radiation at a maximum power of $800 \mathrm{~W}$, heating rate of $30{ }^{\circ} \mathrm{C} \mathrm{min}^{-1}$. The asprepared solution was subjected to a microwave hydrothermal synthesis temperature of $160{ }^{\circ} \mathrm{C}$ for $10 \mathrm{~min}$, and cooled in air at room temperature. After hydrothermal reaction, the obtained precipitate powder was washed several times with distilled water and isopropyl alcohol and then dried at $60{ }^{\circ} \mathrm{C}$ for $24 \mathrm{~h}$.

The crystal structures of the samples were characterized using X-ray diffraction (XRD) performed in the range of $2 \theta=30^{\circ}-80^{\circ}$ in steps of $0.02^{\circ}$ at 5 s/step using CuK $\alpha$ radiation $(\lambda=$ $1.5418 \AA$ ) and a LiF(100) monochromator in a Rigaku Ultima IV diffractometer. The determination of the lattice parameters and the occupation factor over the structure were performed by using the Rietveld method as implemented by the General Structure Analysis System (GSAS) software package with the graphical user interface EXPGUI. ${ }^{29,} 30$ The morphology and the grain size distribution were determined by using a JEOL JM-2100F high resolution transmission electron microscope (HRTEM); the effective Co concentration $\left(x_{\mathrm{E}}\right)$ were estimated by energy dispersive Xray spectrometry (EDS), Oxford XMAX 50 detector; the spatial map of the Co distribution in the nanoparticles were conducted via electron energy-loss spectroscopy (EELS), GATAN GiF Tridiem 863 image filter; and the structure of the samples were also evaluated by selected area electron diffraction (SAED). These analyses were conducted at the Brazilian Nanotechnology National Laboratory (LNNano). Raman scattering spectroscopy was used to study the incorporation of dopants and the resulting lattice disorder in the $w$ - $\mathrm{ZnO}$ host strucure. The Raman measurements were carried out at room temperature in a Jobin-Yvon-64000 micro-Raman system in the backscattering geometry, using the $488 \mathrm{~nm}$ line of an $\mathrm{Ar}^{+}$laser for excitation. X-ray absorption spectroscopy (XAS) analyses was employed to determine the oxidation state (XANES - X-ray NearEdge Spectroscopy) and to assess the environment (EXAFS - Extended X-ray Absorption Fine Structure) of the Co atoms into the $w$ - $\mathrm{ZnO}$ structure. These measurements were performed at the Co K-edge in transmission mode using a $\mathrm{Si}(111)$ channel-cut monochromator at the XAFS2 beamline from the Brazilian Synchrotron Light Laboratory (LNLS). We have employed the Multiplatform Applications for XAFS (MAX) ${ }^{31}$ software package and the FEFF9 code $^{32}$ in the EXAFS analyses. The magnetic measurements were performed using a superconducting quantum interference device magnetometer (SQUID). 


\section{THEORETICAL CALCULATIONS}

The structural and magnetic properties of the nanostructured $\mathrm{Zn}_{1-x} \mathrm{Co}_{x} \mathrm{O}$ samples were also investigated by means of first-principles calculations based on density functional theory (DFT). ${ }^{33}$ Spin-polarized calculations were performed using the local density approximation (LDA), ${ }^{34,35}$ which has been used in previous first-principles calculation of $\mathrm{ZnO}$ nanoparticles. ${ }^{36,}{ }^{37}$ We used the Siesta code $^{38}$ which employs norm-conserving Troullier-Martins pseudopotentials ${ }^{39}$ and linear combinations of atomic orbitals. We used a double-zeta basis set with polarization functions (DZP) for all atoms and a real-space energy cutoff of $200 \mathrm{Ry}$. We considered $w$-ZnO nanoparticles with 80 atoms (40 $\mathrm{Zn}$ and $40 \mathrm{O}$ ), simulated within the supercell approach with a vacuum of $\sim 10 \AA$ between the nanoparticle and its image. The dangling bonds at the surface of the nanoparticle were kept unsaturated and the atoms were allowed to relax to their minimum energy configurations. It was considered one and two substitutional Co impurities at $\mathrm{Zn}$ sites, which correspond to Co concentrations of 2.5 and $5.0 \%$, respectively; these concentrations are in the range of those samples studied in this report (between 0.5 and $7 \%$ ). All atomic positions were fully relaxed until the forces on each atom were smaller than $0.02 \mathrm{eV} / \AA$.

\section{RESULTS AND DISCUSSION}

\subsection{X-ray diffraction}

Figure 1 shows the experimental X-ray diffraction (XRD) and the theoretical refined Rietveld patterns obtained for the studied set of samples. The experimental and fitted patterns difference is also presented in Figure 1. All the observed diffraction peaks are indexed to those of the hexagonal $w$-ZnO structure, space group $P 6_{3} m c$ (JCPDS 36-1451). No traces of metallic Co or any other secondary phases can be detected within the XRD detection limit. The Rietveld refinement was performed by taken initially the $\mathrm{Zn}^{2+}$ and $\mathrm{O}^{2-}$ ions located at $(1 / 3,2 / 3,0)$ and $(1 / 3,2 / 3, z)$, respectively. Table 1 presents the fitted cell parameters and the Rietveld statistics $\left(\chi^{2}\right.$ and $\left.R_{\mathrm{B}}\right)$, which indicate a good agreement between the experimental and calculated patterns. We do not observed any changes in the cell parameters as a function of doping and these data are very similar to those reported for pure $\mathrm{ZnO} .^{40}$ The Rietveld results are an indication that the crystal radius of the Co ions in the samples is quite close to that for the $\mathrm{Zn}^{2+}$ ions in the $w$ - $\mathrm{ZnO}$ lattice $(0.74 \AA) .{ }^{41}$ In fact, by considering that the Co ions in the samples have a +2 oxidation state and takes the tetrahedral sites 
of the $\mathrm{Zn}^{2+}$ in the $w$ - $\mathrm{ZnO}$ lattice (substitutional doping), its crystal radius is $0.72 \AA{ }^{41}$ a value that would lead to only small or not significant changes in the $w$-ZnO structure, as observed. Therefore, the $\mathrm{XRD}$ results indicate that the $\mathrm{Co}$ ions in our nanostructured $\mathrm{Zn}_{1-x} \mathrm{Co}_{x} \mathrm{O}$ samples have a +2 oxidation state and are located at the sites of the $\mathrm{Zn}^{2+}$ cations (Wyckoff position) with no secondary or segregated phases. The +2 oxidation state of the Co ions was further confirmed from the local structure analysis performed via X-ray absorption measurements (XANES). Our DFT calculations also found no significant changes in the $w$-ZnO structure assuming the $\mathrm{Zn}$ substitutional character of the Co doping.

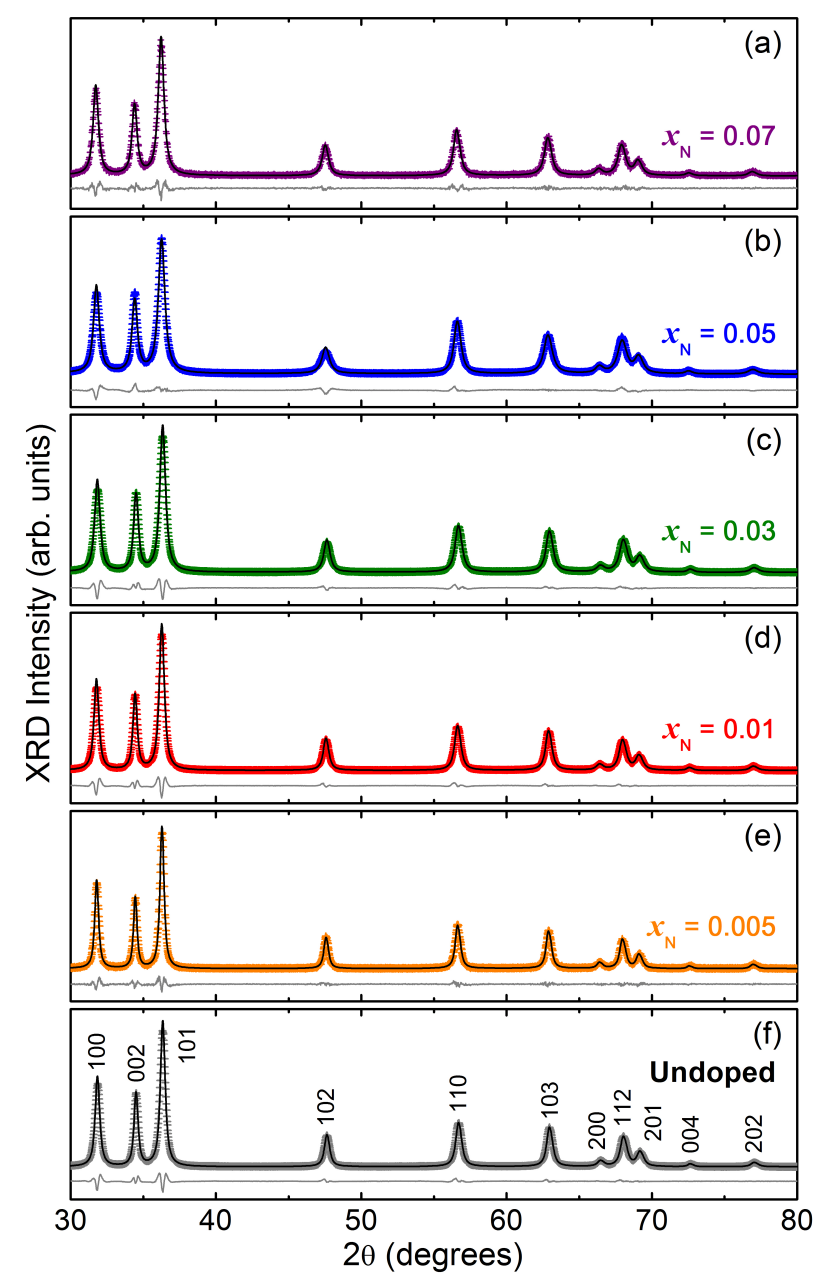

Figure 1. Refined XRD diffractograms of the nanostructured $\mathrm{Zn}_{1-x} \mathrm{Co}_{x} \mathrm{O}$ samples: (a) $x_{\mathrm{N}}=0.07$, (b) 0.05, (c) 0.03, (d) 0.01, (e) 0.005 and (f) undoped ZnO. Each figure shows the observed pattern (symbols), Rietveld calculated pattern (solid line), and the goodness of the fit or residual pattern (at the bottom).

Table 2 presents the elemental occupation factors obtained also from the Rietveld refinement. Estimative of concentrations of defects related to vacant sites and the Co concentration in the samples can be inferred form the occupation factors. It is observed that the Co content are quite close to the Co nominal concentration $\left(x_{\mathrm{N}}\right)$ and there is no detection of significant vacancies at both 
$\mathrm{Zn}$ and $\mathrm{O}$ sites. However, considering the intrinsic errors involved in the refinement process, we can state, at least, a low density of such kind of defects in our set of samples.

Table 1. Structural data ( $a$ and $c$ ) for the nanostructured $\mathrm{Zn}_{1-x} \mathrm{Co}_{x} \mathrm{O}$ samples obtained through the Rietveld refinement. $V$ is the cell volume, $\chi^{2}$ is the square of goodness-of-fit indicator, and $R_{\mathrm{B}}$ is the refinement quality parameter. $\chi_{\mathrm{N}}$ is the nominal Co concentration.

\begin{tabular}{cccccc}
\hline$\chi_{\mathrm{N}}$ & $a(\AA)$ & $c(\AA)$ & $V\left(\AA^{3}\right)$ & $\chi^{2}$ & $R_{\mathrm{B}}$ \\
\hline Undoped & $3.2532(4)$ & $5.213(1)$ & $47.776(1)$ & 8.33 & 1.47 \\
0.005 & $3.2545(4)$ & $5.215(1)$ & $47.835(1)$ & 8.48 & 1.90 \\
0.010 & $3.2538(4)$ & $5.213(1)$ & $47.798(1)$ & 8.72 & 1.49 \\
0.030 & $3.2540(4)$ & $5.213(1)$ & $47.803(1)$ & 8.43 & 1.46 \\
0.050 & $3.2553(1)$ & $5.218(1)$ & $47.889(1)$ & 8.11 & 2.19 \\
0.070 & $3.2560(1)$ & $5.215(1)$ & $47.878(1)$ & 9.77 & 2.42 \\
\hline
\end{tabular}

Table 2. Elemental occupation factor for the nanostructured $\mathrm{Zn}_{1_{-x}} \mathrm{Co}_{x} \mathrm{O}$ samples obtained through Rietveld refinement.

\begin{tabular}{ccccc}
\hline$\chi_{\mathrm{N}}$ & $\mathrm{Zn}$ & $\mathrm{Co}$ & $\mathrm{Zn}+\mathrm{Co}$ & $\mathrm{O}$ \\
\hline Undoped & $1.001(1)$ & - & - & $0.997(5)$ \\
0.005 & $0.996(2)$ & $0.004(2)$ & $1.000(4)$ & $0.990(1)$ \\
0.010 & $0.991(1)$ & $0.012(1)$ & $1.003(2)$ & $0.988(5)$ \\
0.030 & $0.972(1)$ & $0.039(1)$ & $1.011(2)$ & $0.982(5)$ \\
0.050 & $0.957(1)$ & $0.056(1)$ & $1.013(2)$ & $0.979(4)$ \\
0.070 & $0.929(3)$ & $0.071(3)$ & $1.000(6)$ & $0.990(1)$ \\
\hline
\end{tabular}

\subsection{Electron microscopy and elemental analyses}

The morphology of the samples were evaluated by means of transmission electron microscopy (TEM) measurements. Figure 2(a) shows a representative TEM micrograph for the sample with $x_{\mathrm{N}}=$ 0.07. In a general way, the set of samples are composed of round shaped (multifaceted) nanoparticles with diameter of less than $30 \mathrm{~nm}$. SAED measurements were also performed (inset in Figure 2(a)). Figure 2(b) present the correspondent azimuthal integration along the interplanar distance. Here, all the observed diffraction peaks are associated to the $w$ - $\mathrm{ZnO}$ structure. To check the effective Co concentration in the nanostructured $\mathrm{Zn}_{1-x} \mathrm{Co}_{x} \mathrm{O}$ samples, as well as to probe the possible presence of secondary phases, fraction of the samples were cold pressed in the form of pellets and 
EDS analyses were carried out over large areas on the surface of the pellets. The measured average effective Co concentrations $\left(x_{\mathrm{E}}\right)$ listed in Table 3 are in good agreement with the nominal stoichiometry $\left(x_{\mathrm{N}}\right)$ of the samples. It is worth point out that EDS analyses, within their detected limits, do not reveal any evidence of crystallographic secondary phase. These results also suggest that the Co ions in the studied samples are in substitutional character to the $\mathrm{Zn}^{2+}$ ions into the $w$ - $\mathrm{ZnO}$ lattice, in good agreement with XRD results.

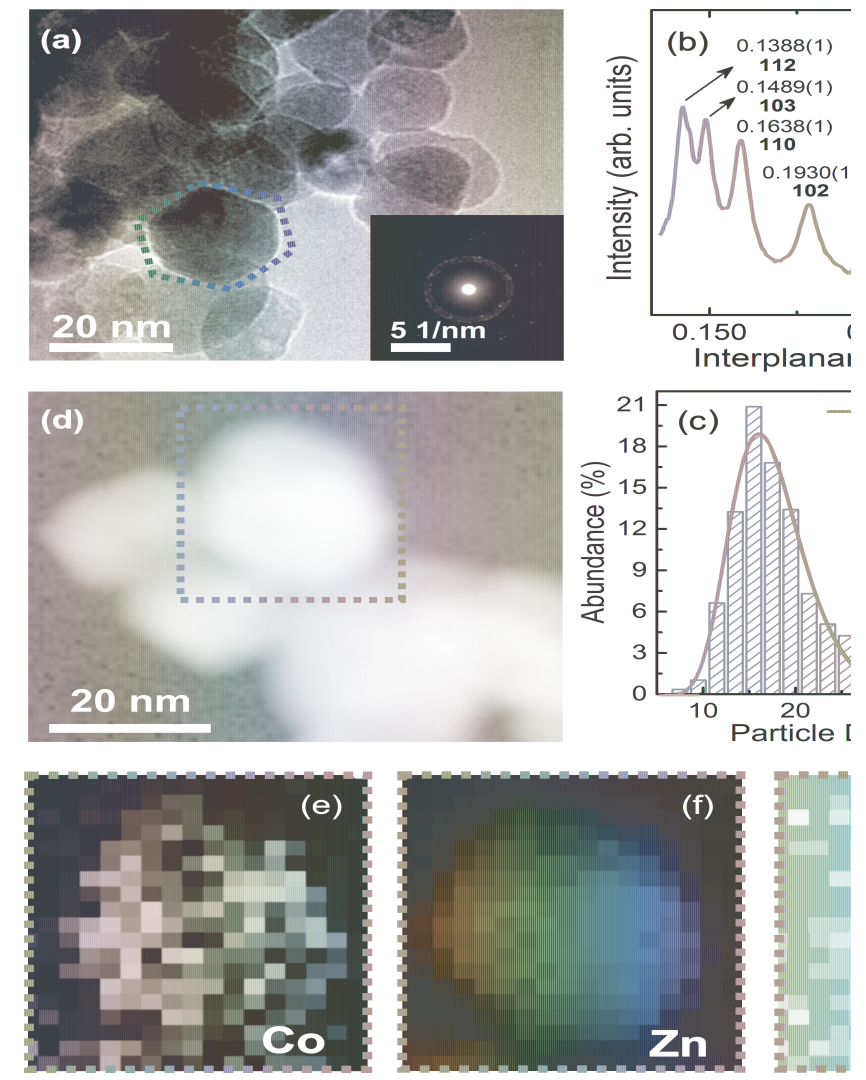

Figure 2. (a) Representative TEM micrograph of nanostructured $\mathrm{Zn}_{1-x} \mathrm{Co}_{x} \mathrm{O}$ sample with $x_{\mathrm{N}}=0.07$. The inset in (a) shows a SAED pattern obtained for this sample, and (b) the correspondent azimuthal integration intensity as a function of the interplanar distance. The cell parameters $a$ and $c$ were taken from the Rietveld refinement results (Table 1). (c) Particle size distribution histogram. The line in panel (c) is the log-normal fit. (e) Cobalt and (f) zinc elemental mapping obtained by EELS in the grain highlighted in TEM micrograph in panel (d) by the dotted green line. (g) Intensity ratio map $\mathrm{Co} / \mathrm{Zn}$ (dark pixels correspond to smaller Co/Zn ratios).

Figure 2(c) shows the obtained histogram used for the statistical analyses of the grain diameter distribution. The images and statistical data for the other samples are similar to those shown in Figure 2(a), 2(b) and 2(c) and are summarized in Table 3. We observe that by increasing the Co content the mean diameter of the nanoparticles decreases. Such behavior has already been reported in nanostructured systems based on $\mathrm{ZnO}^{42} \mathrm{SnTe}^{43}$ and also on $\mathrm{TiO}_{2}$ in the anatase phase doped with 
$\mathrm{Eu}^{44}$ and $\mathrm{La}^{45}$. The Co spatial distribution in the nanoparticles were also mapped via state-of-the-art elemental analysis by means of electron energy-loss spectroscopy (EELS). We followed the procedures described by Wang et al.. ${ }^{46}$ The obtained results are presented in Figures 2(e), 2(f) and 2(g). The bright edges in Figure 2(g), which correspond to the Co/Zn ratio, reveal the Co richness near/at the surface (outer shells) of the nanoparticle. The same analysis on other nanoparticles confirms the Co distribution inhomogeneity. The magnetic results (discussed in the section 4.5) also indicate an inhomogeneity in Co distribution along the volume of the nanoparticles.

Table 3. Particle size distribution analyses. $d$ is the mean value of the particles diameter and $\sigma_{\mathrm{g}}$ is the geometric standard deviation obtained by the log-normal fit of particle size distribution histograms for each sample. $N$ is the total number of the counted particles. $x_{\mathrm{E}}$ is the effective Co concentration measured by EDS. The presented error for the $\chi_{\mathrm{E}}$ data correspond to the standard error of the mean.

\begin{tabular}{ccccc}
\hline $\boldsymbol{x}_{\mathbf{N}}$ & $\boldsymbol{x}_{\mathrm{E}}$ & $\boldsymbol{d}(\mathbf{n m})$ & $\boldsymbol{\sigma}_{\mathbf{g}}$ & $N$ \\
\hline Undoped & - & $26.5(4)$ & $1.40(7)$ & 253 \\
0.005 & $0.006(2)$ & $26.4(5)$ & $1.32(3)$ & 300 \\
0.010 & $0.011(2)$ & $19.3(4)$ & $1.35(3)$ & 280 \\
0.030 & $0.027(3)$ & $18.3(4)$ & $1.35(3)$ & 208 \\
0.050 & $0.055(2)$ & $16.9(1)$ & $1.42(6)$ & 589 \\
0.070 & $0.072(4)$ & $14.9(6)$ & $1.25(1)$ & 108 \\
\hline
\end{tabular}

Generally, the growth of nanoparticles depends on the diffusion of the monomers in the precursor solution to the surface of the growing nanoparticle and on the surface reaction. ${ }^{47}$ In such a way, the concentration of the Co ions in the surface of the nanoparticles explains the decrease of the main diameter with the increase of the Co content by an effect of surface passivation. This kind of effect has been reported previously by different capping/passivating agents. ${ }^{48-50}$ The passivation of the $\mathrm{ZnO}$ surface by the Co ions also explains the usual observed reduction of the $\mathrm{ZnO}$ photocatalytic activity under Co and other transition metals (TM) doping in relatively small (< $50 \mathrm{~nm})$ nanoparticles ${ }^{51-53}$ and, as mentioned in the Introduction section, explain also the quenching of the $\mathrm{ZnO}$ visible fluorescence by the passivation of the correspondent surface defects. ${ }^{11-13}$ 


\subsection{Raman scattering spectroscopy}

Raman spectra from our nanostructured $\mathrm{Zn}_{1-x} \mathrm{Co}_{x} \mathrm{O}$ samples are shown in Figure 3(a) and 3(b). The spectra were normalized by the main vibrational mode $\mathrm{E}_{2 \mathrm{H}}$. For the undoped $\mathrm{ZnO}$ sample (Figure 3(a)) we observe a series of modes centered at 329, 383, 412, 437, 537, 570, 584 and 662 $\mathrm{cm}^{-1}$, that are assigned to the first and second order $w$-ZnO modes: $2 \mathrm{E}_{2 \mathrm{~L}}$ at M-point of the Brillouin zone (BZ), A1(TO), E1(TO), $\mathrm{E}_{2 \mathrm{H}}, 2 \mathrm{LA}$ also at M-point of the BZ, $\mathrm{A}_{1}(\mathrm{LO}), \mathrm{E}_{1}(\mathrm{LO})$ and TA+LO, respectively. ${ }^{54}$ A significant result from the Raman data for the doped samples (Figure 3(b)) is the complete absence of modes related to segregated secondary phases $\left(\mathrm{CoO}\right.$ and $\left.\mathrm{Co}_{3} \mathrm{O}_{4}\right)$. The Raman scattering results, together with the XRD data and the electron microscopy analysis, are strong evidences that Co ions in our samples are incorporated into the $w$-ZnO lattice. Special attention has to be payed to the broad band between 500 and $600 \mathrm{~cm}^{-1}$. This broad band enclose several modes, whereas the main ones are centered approximately at 540 (S', left shoulder) and $570 \mathrm{~cm}^{-1}$ (LO, right shoulder).

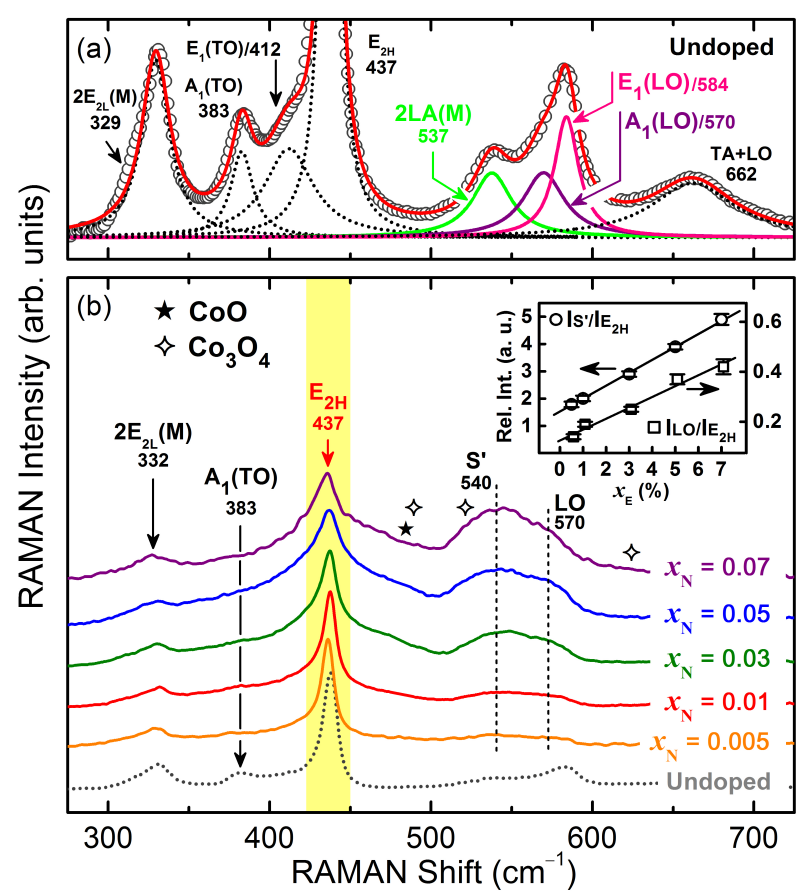

Figure 3. Raman scattering spectra obtained at room temperature for the nanostructured (a) undoped $\mathrm{ZnO}$ and (b) $\mathrm{Zn}_{1-x} \mathrm{Co}_{x} \mathrm{O}$ samples. The spectra were acquired at room temperature and are normalized by the $E_{2 \mathrm{H}}$ vibrational mode. The spectrum for the undoped sample is also shown in (b) for comparison. The inset (b) presents the relative intensity of the S' and LO modes as a function of the effective Co concentration $\left(x_{\mathrm{E}}\right)$. The intensities were obtained via multipeak Lorentz fittings. The symbols $\star$ and $\diamond$ mark the position of the main modes related to the $\mathrm{Co}$ oxides, $\mathrm{CoO}$ end $\mathrm{Co}_{3} \mathrm{O}_{4}$, respectively. ${ }^{16}$

We observe that the relative intensity of these modes scales linearly with Co content in the samples (inset of Figure 3(b)), in agreement with our previous results reported for Co-doped $\mathrm{ZnO}$ 
bulk ceramics ${ }^{16}$. The appearance of this broad band and its dependence on the dopant concentration is also observed for different doping elements: $\mathrm{H},{ }^{55} \mathrm{~N},{ }^{55}{ }^{56} \mathrm{P},{ }^{57} \mathrm{Mn},{ }^{58} \mathrm{Ni},{ }^{59} \mathrm{Cu},{ }^{60} \mathrm{Ga},{ }^{56} \mathrm{Ag},{ }^{61}$ and $\mathrm{Sb},{ }^{62}$ just to mention a few. There are also reports showing the activation of these modes in undoped $\mathrm{ZnO}$ via mechanical milling. ${ }^{63,}{ }^{64}$ Special remarks can be made considering ion implanted $\mathrm{ZnO}$ samples where, besides the dopant incorporation, the irradiation process leads to inevitable structural defects, and that after annealing the broad band completely disappears. ${ }^{56,57}$ These data lead us to infer that the observation of these modes is related to structural defects introduced in the $w$ - $\mathrm{ZnO}$ lattice due to the dopant incorporation or due to the extrinsic structural damage. However, it is interesting to note that the nature of the modes in the observed broad band is different. Doped $\mathrm{ZnO}$ samples usually exhibit a more pronounced left shoulder, ${ }^{16}$ as in the present case; besides, for structurally damaged samples, on the other hand, the right shoulder is more intense. ${ }^{56,63}$ And, in fact, the indexation of the vibrational modes in this region of the spectrum is a highly controversial issue. Schumm et al. ${ }^{58}$ identified for the $\mathrm{Zn}_{1-x} \mathrm{Mn}_{x} \mathrm{O}$ system at the left shoulder the presence of an activated $\mathrm{ZnO}$ mode at $528 \mathrm{~cm}^{-1}$, tentatively assigned to the $2 \mathrm{~B}_{1 \mathrm{~L}}$, and an additional mode at $519 \mathrm{~cm}^{-1}$ that could be assigned to local vibrational mode (LVM) of Mn substitutionally incorporated in the $w$-ZnO lattice. In turn, the mode at $570 \mathrm{~cm}^{-1}$ can be attributed to the overlap of the LO phonons of the $\mathrm{A}_{1}$ (predominant) and $\mathrm{E}_{1}$ modes. In pure $\mathrm{ZnO}$, the $\mathrm{A}_{1}(\mathrm{LO})$ and $\mathrm{E}_{1}(\mathrm{LO})$ modes are usually very weak (Figure $3(\mathrm{a})$ ) due to the destructive interference between the deformation and the Frölich potentials. ${ }^{65}$ Nevertheless, the scattering cross section of these modes can be amplified by the presence of intermediated electronic states in the band gap related to bound excitons created due the introduction of defects and impurities, ${ }^{55}$ an extrinsic Frölich interaction. ${ }^{66}$

\subsection{X-ray absorption}

Figure 4 shows the XANES spectra obtained for the nanostructured $\mathrm{Zn}_{1-x} \mathrm{Co}_{x} \mathrm{O}$ samples at the Co $K$-edge and for reference Co oxides (vertically shifted for clarity). We observe in the spectra that the Co absorption edge for studied samples compares with that of the $\mathrm{CoO}$ reference sample, which lead us to conclude that the Co ions predominantly have a +2 oxidation state in our nanostructured samples. All the spectra have similar features, an indication that there is no significant structural 
distortion around the Co ions for different doping levels; similar behavior was also observed in the DFT calculations when all the atoms around Co are relaxed. The calculated bond length of Co-O is $1.93 \AA$ (comparable with the extracted EXFS data presented in Table 4) which is only slightly smaller than the calculated Zn-O bond length of $2.0 \AA$. Similarly, no significant change in the bond angles was observed via DFT calculations: the O-Co-O bond angle is $124^{\circ}$, which is comparable with the O-Zn-O bond angle of $125^{\circ}$.

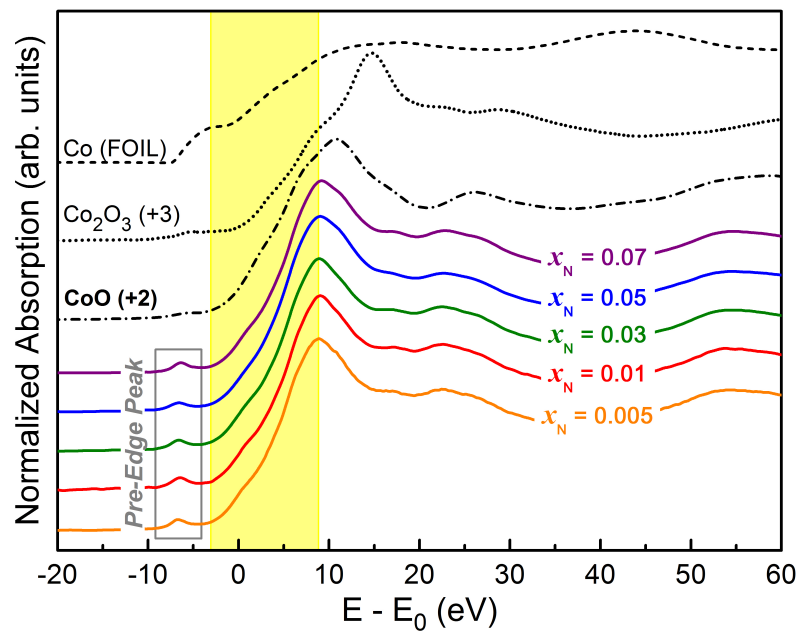

Figure 4. Co $K$-edge XANES spectra of the nanostructured $\mathrm{Zn}_{1-x} \mathrm{Co}_{x} \mathrm{O}$ samples $\left(E_{0}=7708.8 \mathrm{eV}\right)$. Spectra of metallic Co, rocksalt $\mathrm{CoO}$ (oxidation state +2 ) and $\mathrm{Co}_{2} \mathrm{O}_{3}$ (oxidation state +3 ) are also shown for comparison.

We also note a small absorption peak at the pre-edge region. The Co $K$-edge absorption spectrum is related to electrons transitions from the $1 s(I=0)$ state to $4 p(I=1)$ empty states. Besides, the pre-edge region is related to electrons transitions from the $1 s$ to $3 d(I=2)$ states. Although this transition is originally forbidden $(\Delta / \neq \pm 1)$, it occurs due to the hybridization of the Co $3 d$ states with $\mathrm{O} 2 p$ in the sites without an inversion center of symmetry. ${ }^{67}$ In the wurtzite structure the $\mathrm{Zn}$ ions assume a +2 oxidation states and are located in tetrahedral sites, with no inversion center of symmetry, surrounded by four $\mathrm{O}^{2-}$ ions. Therefore, the +2 oxidation state for the Co ions and the observation of the pre-edge peak strongly indicate that the Co ions are taking place of the $\mathrm{Zn}$ ions in the lattice of our nanostructured $w$-ZnO samples.

Figure 5 presents the modulus of the $k^{3}$ weighted Fourier transform (FT) that were extracted from the Co $K$-edge spectra for the nanostructured $\mathrm{Zn}_{1_{-x}} \mathrm{Co}_{x} \mathrm{O}$ samples, a Co foil and the Co oxides and the spectrum obtained at the $\mathrm{Zn} K$-edge for an undoped $\mathrm{ZnO}$ sample. The obtained data reveals that qualitatively there are no significant changes in the crystallographic environment for the Co- 
doped samples as a function of the Co-doping. In addition, these data are also quite different from that obtained for the Co references (Co foil and Co oxides), and, in contrast, resembles the obtained data for the undoped $\mathrm{ZnO}$ sample at the $\mathrm{Zn} K$-edge. These observations led us to conclude that the $\mathrm{Co}^{2+}$ ions in the doped samples are placed in the $\mathrm{Zn}^{2+}$ sites in the $w$ - $\mathrm{ZnO}$ lattice. The theoretical analyses of the Fourier transforms for the Co-doped samples were performed via Multi-Platform Applications for X-ray absorption (MAX), ${ }^{31}$ and FEFF9 code. ${ }^{32}$ The details of the procedures were described before. ${ }^{68}$ It is observed in Figure 5 a good agreement between experimental data (symbols) and theoretical results (lines). Table 4 lists the parameters obtained from the best fits to the data. The first shell (Co-O) coordination number is 4 , consistent with a substitution for tetrahedral $\mathrm{Zn}^{2+}$ ions in the $w$-ZnO structure; additionally, according to our calculations the interatomic distances are not affected by the Co-doping, confirming the XRD Rietveld, XANES structural analyses, and also consistent with our DFT calculations.

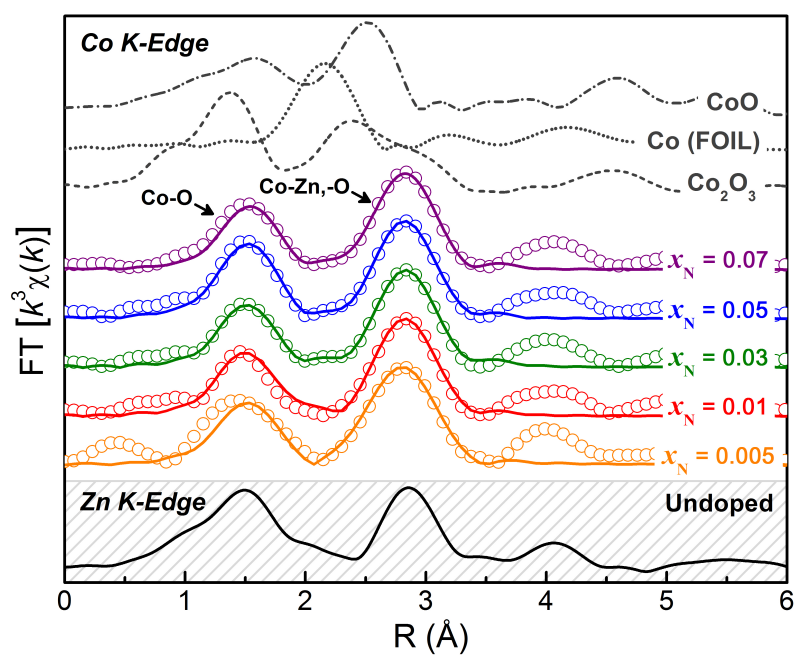

Figure 5. Corresponding $k^{3}$ weighted Fourier transforms (FT) of the X-ray absorption spectra obtained at $\mathrm{Co}$ and $\mathrm{Zn} K$-edge for the nanostructured $\mathrm{Zn}_{1-x} \mathrm{Co}_{x} \mathrm{O}$ samples and reference materials. Open symbols are the experimental data and the solid lines represent the fittings using the parameters shown in Table 2. The spectra are offset for clarity.

In summary, the structural analysis confirms that the $\mathrm{Co}^{2+}$ ions occupy the $\mathrm{Zn}$-sites of the $w$ - $\mathrm{ZnO}$ lattice in our nanostructured $\mathrm{Zn}_{1-x} \mathrm{Co}_{x} \mathrm{O}$ samples. Clearly the results exclude the presence of magnetic extrinsic sources, such as Co-rich nanocrystals or segregated secondary magnetic phases. The size distribution analysis and the EELS results point that, in spite of the Zn substitutional character of the Co-doping, the Co distribution is not homogeneous, concentrating near/at the surface of the nanoparticles. With these conclusions we proceed to the magnetic characterization. 
Table 4. Co $K$-edge EXAFS simulation results obtained by assuming the $\mathrm{Co}^{2+}$ at $\mathrm{Zn}^{2+}$ sites in the $\mathrm{ZnO}$ matrix. $R$ is the distance from the central atom, $N$ is the average coordination number, $\sigma^{2}$ the Debye-Waller factor and $Q F$ the quality factor.

\begin{tabular}{|c|c|c|c|c|c|}
\hline$x_{\mathrm{N}}$ & Shell & $R(\AA)$ & $N$ & $\begin{array}{c}\sigma^{2} \\
\left(\times 10^{-3}\right. \\
\left.\AA^{2}\right) \\
\end{array}$ & $Q F$ \\
\hline \multirow{4}{*}{$\begin{array}{c}0.00 \\
5\end{array}$} & Co-O & $1.99(2)$ & $4.7(7)$ & $8(2)$ & \multirow{4}{*}{3.52} \\
\hline & $\begin{array}{l}\text { Co- } \\
\text { Zn }\end{array}$ & $3.19(4)$ & $6(4)$ & $9(1)$ & \\
\hline & $\begin{array}{l}\text { Co- } \\
\text { Zn }\end{array}$ & $3.23(7)$ & $5(3)$ & $9(1)$ & \\
\hline & Co-O & $3.75(2)$ & $10(2)$ & $8(2)$ & \\
\hline \multirow{4}{*}{0.01} & Co-O & $1.95(1)$ & $4.2(7)$ & $6(2)$ & \multirow{4}{*}{1.67} \\
\hline & $\begin{array}{l}\text { Co- } \\
\text { Zn }\end{array}$ & $3.20(5)$ & $5(7)$ & $8(1)$ & \\
\hline & $\begin{array}{l}\text { Co- } \\
\text { Zn }\end{array}$ & $3.22(7)$ & $5(4)$ & $8(1)$ & \\
\hline & Co-O & $3.72(2)$ & $8(4)$ & $6(2)$ & \\
\hline \multirow{4}{*}{0.03} & Co-O & $1.97(1)$ & $4.2(6)$ & $5(2)$ & \multirow{4}{*}{1.27} \\
\hline & $\begin{array}{l}\text { Co- } \\
\text { Zn }\end{array}$ & $3.22(1)$ & $5(2)$ & $7(3)$ & \\
\hline & $\begin{array}{l}\text { Co- } \\
\text { Zn }\end{array}$ & $3.20(3)$ & $4(4)$ & $7(3)$ & \\
\hline & Co-O & $3.72(3)$ & $11(2)$ & $5(2)$ & \\
\hline \multirow{4}{*}{0.05} & Co-O & $1.98(2)$ & $4.4(6)$ & $7(2)$ & \multirow{4}{*}{0.98} \\
\hline & $\begin{array}{l}\text { Co- } \\
\text { Zn }\end{array}$ & $3.21(1)$ & $6(3)$ & $8(3)$ & \\
\hline & $\begin{array}{l}\text { Co- } \\
\text { Zn }\end{array}$ & $3.10(6)$ & $1(1)$ & $8(3)$ & \\
\hline & Co-O & $3.71(2)$ & $10(2)$ & $7(2)$ & \\
\hline \multirow{4}{*}{0.07} & Co-O & $1.99(1)$ & $4.3(6)$ & $6(2)$ & \multirow{4}{*}{1.14} \\
\hline & $\begin{array}{l}\text { Co- } \\
\text { Zn }\end{array}$ & $3.22(1)$ & $9(1)$ & $9(1)$ & \\
\hline & $\begin{array}{l}\text { Co- } \\
\mathrm{Zn}\end{array}$ & $3.28(3)$ & $2(1)$ & $9(1)$ & \\
\hline & Co-O & $3.77(2)$ & $8(2)$ & $6(2)$ & \\
\hline
\end{tabular}

\subsection{Magnetic characterization}

The magnetic behavior of the studied samples shows features of a paramagnetic phase with large antiferromagnetic (AF) exchange interaction between $\mathrm{Co}^{2+}$ ions. This behavior is similar to other studied diluted magnetic semiconductors (DMS). ${ }^{69-73}$ However, for the undoped ZnO sample and for the samples with lower Co concentration ( $x \leq 0.01)$, a small ferromagnetic (FM) contribution was detected at $T=300 \mathrm{~K}$. Figure 6 presents the $M(H)$ for the undoped $\mathrm{ZnO}, x_{\mathrm{N}}=0.005$ and $x_{\mathrm{N}}=$ 
0.01 samples and the correspondent obtained $M_{\mathrm{S}}$ values. The parameter $M_{\mathrm{S}}$ is the saturation magnetization of the FM contribution. The extraction of the magnetic susceptibility $(\chi)$ for the Cobalt paramagnetic phase and saturation magnetization $\left(M_{\mathrm{S}}\right)$ of the FM phase have been obtained using the following method. The magnetization $(M)$ has been measured at fixed temperature for various low field values above the saturation field of the FM contribution. The collected ramp of $M$ was fitted by a linear regression $\left(M=M_{\mathrm{S}}+\chi_{\mathrm{PD}} H\right)$. The angular coefficient $\chi_{\mathrm{PD}}$ is the susceptibility of the paramagnetic phase $\left(\chi_{\mathrm{P}}\right)$ plus the diamagnetic contribution $\left(\chi_{\mathrm{D}}\right)$ of the $\mathrm{ZnO}$ lattice $\left(\chi_{\mathrm{PD}}=\chi_{\mathrm{P}}+\chi_{\mathrm{D}}\right)$. For all samples, the fit yielded a constant diamagnetic susceptibility $\left(\chi_{D}\right)$ similar to ZnO sample, $\chi_{\mathrm{D}}$ $=-3.45 \times 10^{-7}(\mathrm{emu} / \mathrm{g})$. By this way it was verified that $M_{\mathrm{S}}$ is independent of $T$. For the other samples, no FM contribution has been detected $\left(M_{\mathrm{S}} \approx 0\right)$.

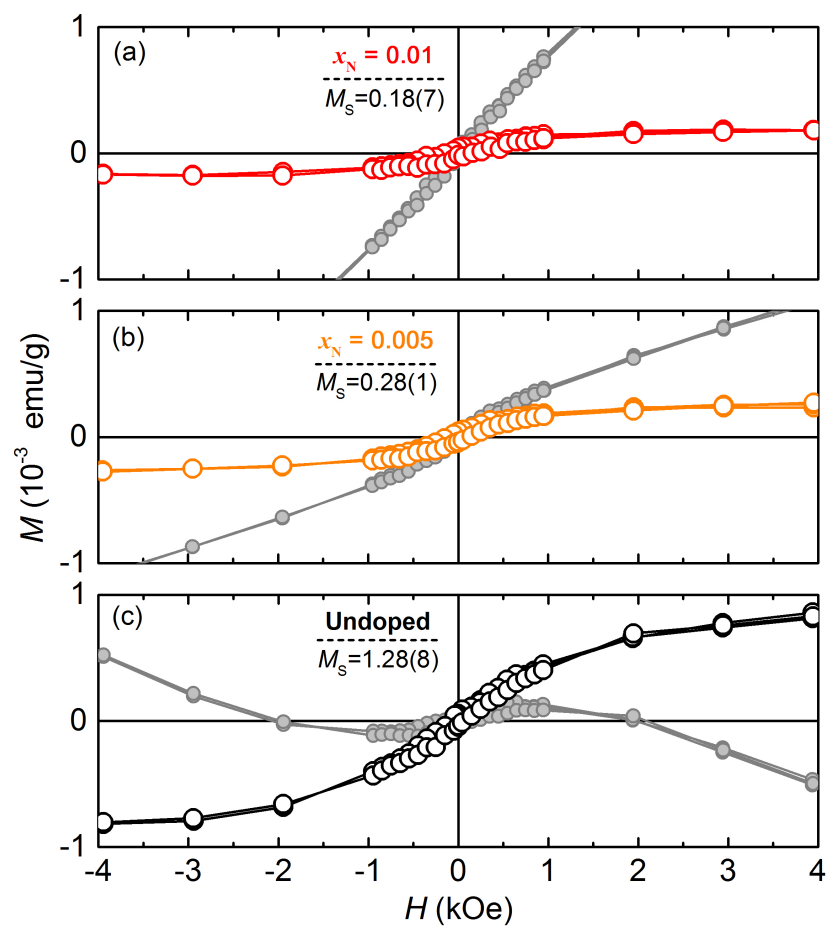

Figure 6. Low field part of the magnetization traces obtained at $T=300 \mathrm{~K}$ for the (a) $x_{\mathrm{N}}=0.01$, (b) $x_{\mathrm{N}}=0.005$ and (c) undoped $\mathrm{ZnO}$ samples. The gray small full symbols correspond to the raw data obtained for the samples before the subtraction of the main diamagnetic (undoped, (a)) and main paramagnetic (doped, (b) and (c)) contribution.

One can find in the literature a great number of reports on the ferromagnetism in undoped $\mathrm{ZnO}$ system. ${ }^{74,75}$ The often small observed FM phase is usually discussed in terms of $d^{0}$ ferromagnetism. ${ }^{76}$ Here, point defects (vacancies or interstices) are the responsible ones for the observed ferromagnetism by means of a spin polarized density of states around the Fermi level. It is a spinsplit impurity band derived from defect states. In this context, many reports argue that the observed 
ferromagnetism is related to oxygen vacancies $\left(V_{0}\right),{ }^{77-79}$ but there are also significant reports considering zinc vacancies $\left(V_{\mathrm{zn}}\right){ }^{80-82}$ revealing the controversial nature of this issue. Besides, Sundaresan et al. suggested that all metal oxides in the nanoparticulate form would exhibit roomtemperature ferromagnetism due to the exchange interactions between unpaired electron spins arising from $V_{\mathrm{O}}$ at the nanoparticle surface. ${ }^{74} \mathrm{Xu}$ et al. showed that defects ( $V_{\mathrm{O}}$ ) located mainly near the surface would be the source of the observed RTFM in undoped $\mathrm{ZnO}$ nanoparticles. ${ }^{79}$ From the theoretical point of view, Schoenhalz et al. proposed that the ferromagnetism in nanostructured materials would be mediated by extended defects, such as surfaces and grain boundaries. ${ }^{37}$ In fact, one can find several reports arguing in favor of this kind of surface magnetism in several different systems. ${ }^{83-86}$ In summary, the origins of magnetism in defective oxides are still under debate.

In order to understand the magnetic results for the undoped $\mathrm{ZnO}$ sample, we have performed DFT calculations on the formation energy $\left(E_{\mathrm{f}}\right)$ and the magnetic moments of $V_{\mathrm{zn}}$ and $V_{\mathrm{O}}$ in the volume $(v)$ and in the surface $(s)$ of the $\mathrm{ZnO}$ nanoparticles. The defect formation energy is given by $E_{\mathrm{f}}=E_{\mathrm{T}, \mathrm{D}}-E_{\mathrm{T}}-\mu_{\mathrm{x}}$, where $E_{\mathrm{T}, \mathrm{D}}$ is the total energy of the nanocrystal with the defect, $E_{\mathrm{T}}$ is the total energy of the nanocrystal without the defect, and $\mu_{\mathrm{X}}$ is the chemical potential of $\mathrm{X}(\mathrm{X}=\mathrm{Zn}$ or $\mathrm{O})$. The obtained values are presented in Table 5. We observe that defects ( $V_{\mathrm{Zn}}$ and $V_{\mathrm{o}}$ ) located in the surface of the nanoparticle have smaller formation energies than those in the volume region. Besides, only $V_{\mathrm{Zn}}$ present magnetic moment in both the volume $(1.95 \mu \mathrm{B} / \mathrm{cell})$ and in the surface $(2.00$ $\mu \mathrm{B} /$ cell) of the nanoparticle. Systems with $V_{\mathrm{O}}$ have zero magnetic moment. These results lead us to infer that only $V_{\mathrm{Zn}}$ would contribute to the observed ferromagnetic phase, and that the concentration of these defects would be higher at the surface of the nanoparticles.

Table 5. DFT calculated formation energies $\left(E_{\mathrm{f}}\right)$ for the zinc $\left(V_{\mathrm{Zn}}\right)$ and oxygen $\left(V_{\mathrm{o}}\right)$ vacancies at $\mathrm{Zn}$ rich and O-rich conditions in the volume $(v)$ region and at the surface $(s)$ of the $\mathrm{ZnO}$ nanoparticle. $M$ is the respective calculated magnetic moment in units of the Bohr magneton per cell.

\begin{tabular}{ccccc}
\hline \multirow{2}{*}{ Defect } & \multicolumn{2}{c}{$E_{\mathrm{f}}(\mathrm{eV})$} & \multirow{2}{*}{$\begin{array}{c}M \\
\end{array}$} \\
\cline { 3 - 4 } & & Zn-rich & O-rich & $(\mu \mathrm{B} /$ cell $)$ \\
\hline \multirow{2}{*}{$V_{\mathrm{Zn}}$} & $v$ & 3.62 & 0.46 & 1.95 \\
& $s$ & 3.41 & 0.25 & 2.00 \\
\hline \multirow{2}{*}{$V_{\mathrm{O}}$} & $v$ & 0.63 & 3.79 & 0.00 \\
& $s$ & 0.42 & 3.59 & 0.00 \\
\hline
\end{tabular}


For the Co-doped samples, we have also solved the Kohn-Sham (KS) equations in the FM and $\mathrm{AF}$ states and we have calculated the energy difference $\left(\Delta E=E_{\mathrm{FM}}-E_{\mathrm{AF}}\right)$ as a function of Co-Co separation. At short distances lower than $\sim 4 \AA$ the dominant interactions between the Co atoms are $\mathrm{AF}$, consistent with our experimental observations. The value of $\Delta E$ can be mapped into a mean field model and one can easily extract the exchange integral constant $J$, which is negative in all cases. For distances larger than $\sim 4 \AA$ a week FM interaction appears. For two Co ions in a nanoparticle separated for more than $4 \AA$ the calculated magnetic moment was $6.16 \mu \mathrm{B} /$ cell. These data, together with the knowledge of the Co agglomeration in the region near/at the surface of the $\mathrm{ZnO}$ nanoparticles, allow us to state that a Co ferromagnetic order would be only possible at very low Co concentrations. We also examined the influence of $V_{\mathrm{zn}}$ on the exchange interactions between the Co atoms, and we found that Co atoms prefer AF interactions even in the presence of $V_{\mathrm{Zn}}$.

Based on our DFT results we do not consider the contribution of the $V_{\mathrm{O}}$ for the observed RTFM and infer that it is, at least in part, related to the $V_{\mathrm{Zn}}$ at the surfaces of the nanoparticles. However, for the undoped $\mathrm{ZnO}$ sample we have measured a saturation magnetization of $1.28 \times 10^{-3} \mathrm{emu} / \mathrm{g}$, considering the calculated magnetic moment associated to $V_{\mathrm{Zn}}$ of $1.95 \mu \mathrm{B}$, the density of $V_{\mathrm{Zn}}\left(N_{\mathrm{Zn}}\right)$ is estimated to be $10^{17} \mathrm{~cm}^{-3}$. Besides, the $N_{\mathrm{Zn}}$ can be also estimated by the relation $N_{\mathrm{Zn}}=N \times$ $\exp \left(-E_{\mathrm{f}} / k_{\mathrm{B}} T\right)$, where $N$ is the number of sites per $\mathrm{cm}^{-3}, E_{\mathrm{f}}$ is the calculated formation energy for the $V_{\mathrm{zn}}, k_{\mathrm{B}}$ is the Boltzmann constant and $T$ is the temperature. At $300 \mathrm{~K}$, and taking into account the calculated $E_{\mathrm{f}}$ listed in Table 5, in the best situation, the calculated $N_{\mathrm{Zn}}$ is no more $10^{14} \mathrm{~cm}^{-3}$. With these simple estimates we conclude that the observed RTFM for the undoped $\mathrm{ZnO}$ sample also cannot be fully explained in terms of the magnetic moments obtained in our DFT calculation. However, for the Co-doped samples ( $x_{\mathrm{N}}=0.005$ and 0.01$)$ the FM phase decreases drastically and disappears for higher Co concentration. Once the magnetic coupling between the Co ions are mainly of AF character, and taking into account the electron microscopy results, showing that the Co ions are concentrated near/at the surface of the nanoparticles, leading to a passivated surface, we reach to the important conclusion that the observed RTFM in our samples are, in fact, mainly due to surface effects, in a kind of surface magnetism related to different defects (not $V_{\mathrm{Zn}}$ and $V_{\mathrm{O}}$ ), and possibly to adsorbed elements. 
The analysis of the paramagnetic phase measured for the set of Co-doped samples gives us also very important information. Figure $7(\mathrm{a})$ shows the inverse of the paramagnetic susceptibility $\left(\mathrm{XP}_{\mathrm{P}}^{-1}\right)$ as a function of the temperature. The diamagnetic contribution of the $\mathrm{ZnO}$ lattice has been subtracted to the data. For all samples, the magnetic susceptibility displays a Curie-Weiss (CW) behavior in the high-temperature range $(120-300 \mathrm{~K}) ; \chi_{\mathrm{P}}=C /(T-\theta)$, where $C$ is the Curie constant and $\theta$ is the CW temperature. Here we label the Co concentration derived from the paramagnetic component analyses as $x_{\mathrm{P}}$ in order to distinguish it from the nominal $\left(x_{\mathrm{N}}\right)$ and the measured effective $\left(x_{\mathrm{E}}\right)$ concentration. The Curie constant is related to the concentration through $C=N\left(g \mu_{\mathrm{B}}\right)^{2} S(S+1) \chi_{\mathrm{P}} / 3 k_{\mathrm{B}}$, where $N$ is the number of cations per gram, $g=2.264$ and $S=3 / 2$ are respectively the isotropic Landé factor and the spin of the $\mathrm{Co}^{2+},{ }^{87,88} \mu_{\mathrm{B}}$ is the Bohr magneton and $k_{\mathrm{B}}$ is the Boltzmann constant.

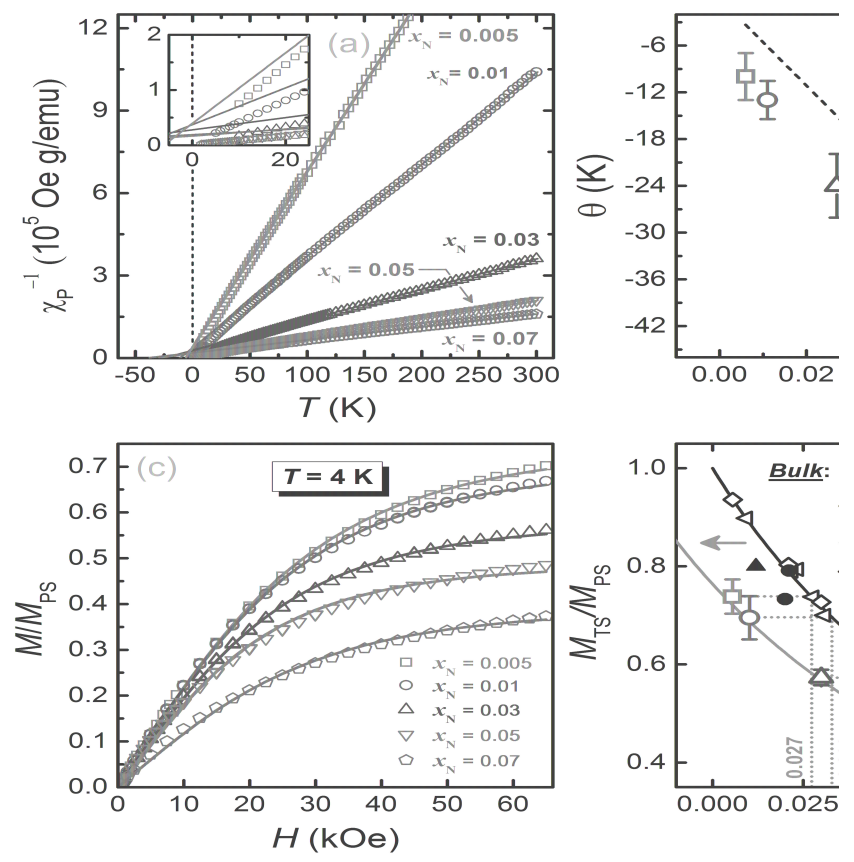

Figure 7. (a) Inverse paramagnetic susceptibility $\left(\chi_{\mathrm{P}}^{-1}\right) v s$. temperature of the paramagnetic phase for the nanostructured $\mathrm{Zn}_{1-x} \mathrm{Co}_{x} \mathrm{O}$ samples. Symbols are the experimental data. The solid lines represent the fit of the data in the high-temperature range to the CW law. The inset highlights the region of low temperature. (b) Experimental $\theta\left(x_{\mathrm{P}}\right)$ obtained from the fit in (a) for all the studied samples. The dashed line represents the result of a linear fit of the experimental data. (c) Magnetization $(M)$ of the samples measured as a function of the magnetic field $(H)$ at $T=4 \mathrm{~K}$. $M$ is normalized to its saturation value $M_{\mathrm{PS}}$ calculated from results of the susceptibility. The symbols represent the experimental results and the lines display fits of the data by using a modified Brillouin function (MBF). (d) Ratio $M_{\mathrm{TS}} / M_{\mathrm{PS}}$ as a function of the concentration $\chi_{\mathrm{P}}$ determined in the present work and for other II-VI DMSs bulk materials. The black line represents the predicted ratio in a model with a dominant AF interaction between first neighbors and based on a random distribution of the magnetic ions, the gray line is the same, but horizontally translated to left (highlighted by the arrow) in order to match the experimental data. (I) from ref. 70, (II) from ref. 89, (III) from ref. 69, (IV) from ref. 73, (V) from ref. 90, (VI) from ref. 72, and (VII) from ref. 91. 
From the fit of the $\chi_{\mathrm{P}}$ to the CW law we obtain the Co concentration $\left(\chi_{\mathrm{P}}\right)$ in good agreement with $x_{\mathrm{N}}$ and $x_{\mathrm{E}}: x_{\mathrm{P}}=0.0055,0.0102,0.030,0.052$ and 0.071 . These results are also an indication in favor to the previous conclusion that the observed RTFM for the undoped sample and for the samples with Co concentration of $x_{\mathrm{N}}=0.005$ and 0.01 are, in fact, not related to the Co doping, since almost all the Co ions in the samples are found in the paramagnetic state. Besides, the values of the CW temperature obtained for all the samples are displayed in the Figure 7(b) as a function of $x_{\mathrm{p}}$. Negative values of $\theta$ indicate that the dominant exchange interaction between Co ions is antiferromagnetic, in accordance with the DFT results. Assuming here a linear dependence of $\theta$ with the concentration $(\theta$ $\left.=\theta_{0} \times x_{\mathrm{P}}\right)$ we obtained $\theta_{0}=-557 \pm 75 \mathrm{~K}$. The exchange constant of first neighbors $\left(J_{1}\right)$ can be estimated using the relation $\theta_{0}=2 z S(S+1) J_{1} / 3 k_{\mathrm{B}}$, where $z$ is the coordination number $(z=12$ for first neighbors in the wurtzite lattice). The obtained value of $J_{1} / k_{\mathrm{B}}=-18.6 \pm 2.5 \mathrm{~K}$ is in quite good agreement with previous reports. ${ }^{16,89,92,93}$

For all samples, and below $100 \mathrm{~K}$, the magnetic susceptibility departs from the CW law in the form of a downturn in the graph of the inverse of the paramagnetic susceptibility versus temperature (inset of Figure 7(a)). This feature is much more pronounced for large Co-doped concentration $\left(x_{\mathrm{N}}\right)$ and is due mainly to the AF coupling between two $\mathrm{Co}^{2+}$ ions (pairs) and other Co clusters with total spin $\left(\mathcal{S}_{\mathrm{T}}\right)$ at ground state equal to zero. ${ }^{94}$ The effect of the AF clustering is also easily detectable in the magnetization curves measured at $T=4 \mathrm{~K}$ displayed in the Figure $7(\mathrm{c})$. Here, $M$ is normalized to its saturation value $M_{\mathrm{PS}}\left(M_{\mathrm{PS}}\right.$ is the theoretical saturation magnetization value considering no relevant exchange interaction between the $\mathrm{Co}^{2+}$ ions, paramagnetic case). $M$ is due mainly to isolated $\mathrm{Co}^{2+}$ ions (singles) and AF clusters with $S_{\mathrm{T}} \neq 0$. At higher fields we observe a decrease of the $M / M_{\mathrm{PS}}$ values with increasing the Co concentration. This feature indicates that the population of singles decreases with increasing the Co concentration, as expected by an AF clustering. The magnetization curves of the samples can be well fitted by a modified Brillouin function (MBF). ${ }^{95}$ This fit gives the value of the technical saturation magnetization $\left(M_{\mathrm{TS}}\right)$. Considering a cluster theoretical model with one AF exchange interaction between first Co neighbors, and assuming a random distribution of the magnetic ions over the cation sites, the ratio $M_{\mathrm{TS}} / M_{\mathrm{PS}}$ can be calculated by 
$M_{\mathrm{TS}} / M_{\mathrm{PS}}=P_{\mathrm{S}}+P_{\mathrm{OT}} / 3+P_{\mathrm{CT}} / 15+P_{\mathrm{PQ}} / 2+P_{\mathrm{FQ}} / 5+P_{\mathrm{O}} / 5$

where $P_{i}$ is the probability that a magnetic ion belongs to each of these $i$ type of cluster: $\mathrm{S}=$ Single, $\mathrm{OT}=$ Open Triplet, $\mathrm{CT}=$ Closed Triplet, $\mathrm{PQ}=$ Propeller Quartet, FQ $=$ Funnel Quartet, Other $=$ cluster larger than quartet. The probabilities $P_{i}$ as a function of concentration can be determined using the cluster tables givin in ref. 96 . Figure $7(\mathrm{~d})$ shows the ratio $M_{\mathrm{TS}} / M_{\mathrm{PS}}$ as a function of $\chi_{\mathrm{P}}$ determined for the studied samples and for other based II-VI DMSs with wurtzite structure. The line represents the calculated ratio using equation (1). Previous works on bulk II-VI DMSs agree quite well with the theoretical model. However, for our nanostructured $\mathrm{Zn}_{1-x} \mathrm{Co}_{x} \mathrm{O}$ samples, the data show a large deviation for lower values of the theoretical curve. By a simple translation of the theoretical curve to lower values in $x_{\mathrm{p}}$, we observe that the obtained experimental data follow the expected behavior predicted by the theoretical model, but considering higher values of dopant concentration, that we call now as local concentration $\left(x_{\mathrm{L}}\right)$. The obtained values are: $x_{\mathrm{L}}=0.027,0.033,0.053,0.073$ and 0.102 for the samples with $x_{\mathrm{N}}=0.005,0.01,0.03,0.05$ and 0.07 , respectively. The result $x_{\mathrm{L}}>x_{\mathrm{N}}$ for all samples indicates a clumped distribution of the Co ions, complementing and confirming the previous structural results related to the inhomogeneity distribution of the Co ions over the volume of the nanoparticle, mainly concentrate at its surface. Therefore, the studied nanoparticles can be described as composed of a pure $\mathrm{ZnO}$ core covered by a $\mathrm{Zn}_{1-x} \mathrm{Co}_{x} \mathrm{O}$ layer with Co concentration $x_{\mathrm{L}}$. Assuming that the Co distribution in the $\mathrm{Zn}_{1-x} \mathrm{Co}_{x} \mathrm{O}$ layer is random, the diameter of the pure $\mathrm{ZnO}$ $\left(d_{\mathrm{ZnO}}\right)$ core can be determined using: $d_{\mathrm{ZnO}}=\left(1-\chi_{\mathrm{P}} / \chi_{\mathrm{L}}\right)^{1 / 3} \times d$, where $d$ is the total diameter (Table 3$)$. So, the thickness of the $\mathrm{Zn}_{1-x} \mathrm{Co}_{x} \mathrm{O}$ layer $(e)$ can then be deduced. We obtained $e=1 \mathrm{~nm}, 1.1 \mathrm{~nm}, 2.2$ $\mathrm{nm}, 2.5 \mathrm{~nm}$ and $2.8 \mathrm{~nm}$ for $x_{\mathrm{N}}=0.005,0.01,0.03,0.05$ and 0.07 , respectively.

\subsection{Growth and doping of the $\mathrm{w}-\mathrm{ZnO}$ nanoparticle}

As presented before, the doping process at nanoscale has been a matter of debate since last

decade. ${ }^{26}$ In this context, two different main models have been discussed, one relates the process to thermodynamic issues, the self-purification effect; ${ }^{97}$ the other one states that the doping process is kinetically controlled. ${ }^{98}$ In the self-purification model the defect formation energy, the energetic cost of the dopant incorporation into the host lattice, increases as the size of the nanoparticle decreases. In 
the process of nucleation and growth of the nanoparticle the picture corresponds to the formation of a dopant-free core and a subsequent increase of the dopant incorporation as the nanoparticle growth, until reach the bulk condition. In the other model, the mechanism that controls the doping is the initial adsorption of dopants on the surface of the nanocrystal during its growth determined by the surface morphology, nanocrystal shape and the surfactants in the growth solution. Besides, most recently, Cheng et al. ${ }^{99}$ gave some important contribution to the understanding of the doping process of nanostructured semiconductors. Based on experimental results they proposed that the doping process would be divided in, at least, four different and independent mechanisms: surface adsorption, lattice incorporation, lattice diffusion and lattice ejection.

Here, to address the question, we calculated via DFT the formation energy $\left(E_{\mathrm{f}}\right)$ for the Co incorporation into the $w$ - $\mathrm{ZnO}$ nanoparticle, in comparison with the formation energy in $\mathrm{ZnO}$ bulk; we followed the procedure described in ref. 97. We found that the formation energies for the incorporation of Co in the volume (inner region) and in the surface of the nanoparticle are, respectively, 2.99 and $3.52 \mathrm{eV}$ lower than in the $\mathrm{ZnO}$ bulk, suggesting that Co incorporation is easier in the nanoparticle than in the bulk system. These results also indicate that, contrary to pointed in ref. 97, the decrease in size favors the doping. Schoenhalz et $a l^{36}$ have obtained similar results also for Co-doped $\mathrm{ZnO}$ nanoparticles, considering non-passivated surfaces the defect formation energy also decreases as the size of the nanoparticle decreases; besides, considering passivated surfaces, they did not obtain any significant changes in the defect formation energy with the size of the nanoparticle. Considering other systems, Li et al. ${ }^{100}$ also shown that, for the ZnSe doping with isovalent elements (Mn and Mg), the changes of the formation energies as a function of the size of the nanoparticle is relatively small. Facing our theoretical results and the above comments, we conclude that the selfpurification model is not an intrinsic and universal property of defects in nanostructured semiconductor, and that the Co incorporation into the nanostructured $\mathrm{ZnO}$, specifically, would be easier, or at least the same, as compared to bulk $\mathrm{ZnO}$. Once the Co solubility in bulk ZnO samples is relatively high, ${ }^{101}$ we would expect a similar behavior at nanoscale. This assumption is confirmed by the observed degree of doping in our nanostructured samples, around $100 \%$, as $x_{\mathrm{N}} \cong x_{\mathrm{E}}$ (Table 3 ). Considering the process of dopant surface adsorption and its subsequent incorporation into the lattice 
of the host matrix separately, ${ }^{99}$ these data $\left(x_{\mathrm{N}} \cong x_{\mathrm{E}}\right)$ give us also some insights about the Co adsorption reaction at the surfaces of the $\mathrm{ZnO}$ nanoparticle. In the kinetically controlled model, ${ }^{98}$ differences in the dopant binding energy related to different surfaces of the nanoparticles lead to a non-homogeneous doping over the nanoparticle volume and, also, to a degree of doping lower than the concentration of the doping element in the growth solution, correspondent to the fraction of the reactive surface with respect to the total surface area of the nanoparticle (taking into account the non/less reactive surfaces). As we are dealing here with rounded shaped (multifaceted) nanoparticles (Figure 2(a)), we can state that Co binding energy is relatively high and independent of the specific $\mathrm{ZnO}$ surface. However, further theoretical studies are necessary in order to corroborate this statement.

Another important result of our calculation is that the $E_{\mathrm{f}}$ is lower at the surface than in the volume of the nanoparticle. These results drive us to inquiry about the barrier diffusion energy ( $\left.E_{\mathrm{d}}\right)$ related to the Co into the $w$-ZnO structure. For the nanoparticle simulated here, the diffusion barrier was computed considering three Zn substitutional sites for the Co impurity: in the volume, in the sub-surface and in the surface. We found that the configuration with Co replacing a Zn atom in the volume of the nanoparticle has total energy $\sim 0.53 \mathrm{eV}$ higher than that with Co at a $\mathrm{Zn}$ site in the surface, and $\sim 0.06 \mathrm{eV}$ lower than that with $\mathrm{Co}$ at a sub-surface site. From these results we estimate that the diffusion barrier for the Co dopant to migrate from the volume to the surface of the nanoparticle (outer direction) is about only $0.06 \mathrm{eV}$, and in the opposite direction (inner direction), from the surface to the volume, is $0.59 \mathrm{eV}$, one order of magnitude higher than in the outer direction. We can estimate the temperature for Co diffusion by using the transition state theory. ${ }^{102}$ Here an atom jumps into a neighbor site over an energy barrier $E_{\mathrm{d}}$ with a frequency $(\Gamma)$ given by $\Gamma=\Gamma_{0} \times$ $\exp \left(-E_{\mathrm{d}} / k_{\mathrm{B}} T\right)$, where $k_{\mathrm{B}}$ is the Boltzmann constant ant $T$ is the temperature. As suggested by Janotti $e t$ al., ${ }^{103}$ the temperature at which a defect becomes mobile can be obtained by taking $\Gamma=1 \mathrm{~s}^{-1}$, by the usual definition of that temperature, and $\Gamma_{0}=10^{13} \mathrm{~s}^{-1}$, a typical phonon frequency. With these values and the calculated $E_{\mathrm{d}}$, we obtain an activation temperature of $\sim 23 \mathrm{~K}$ to diffusion from the volume to surface and $\sim 224 \mathrm{~K}$ in the opposite direction. With these data we can state that at the temperature of synthesis, during the nanoparticle growth and the concomitant Co incorporation, the Co ions will 
easily diffuse along the nanoparticle. However, with lowering the temperature, the Co ions will be trapped at its surface, as the barrier diffusion to come back to the inner region of the nanoparticle is higher $(\sim 0.59 \mathrm{eV})$ than in the outer direction, leading, so, to the experimentally observed Co enriched nanoparticle passivated surface. The Figure 8 presents a static picture of the $\mathrm{ZnO}$ nanoparticle growth and Co incorporation dynamic based on the above assumptions.

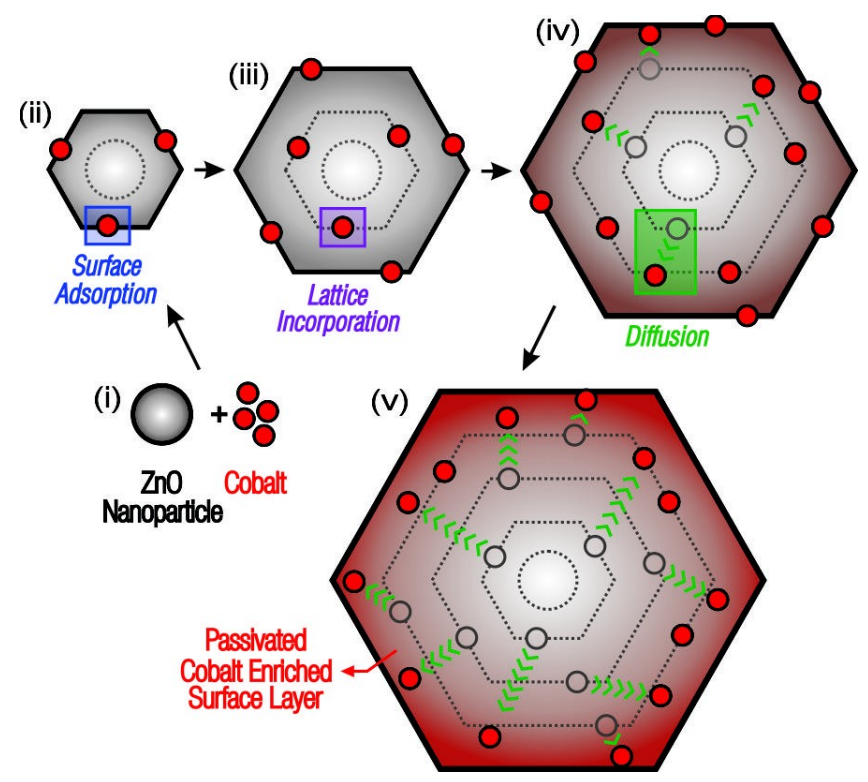

Figure 8. Cross-sectional view (static picture) of the nucleation and growth of a nanoparticle. (i) For small nanocrystals many semiconductors form non-crystalline cage-like clusters, typically with highly stable surfaces that suppress dopant adsorption. ${ }^{98}$ (ii) As the nanoparticle growths, under equilibrium, a faceted nanoparticle evolves and Co ions start adsorbing into its surface. (iii) In the subsequent growth of the nanoparticle the adsorbed Co ion is incorporated into the ZnO lattice. (iv) Due to relative lower value of the Ed the Co ions start to diffuse along the volume of the nanoparticle. (v) Once in the region close to the surface, the Co ions end up trapped as the barrier of diffusion back to the inner region of the nanoparticle is higher than in the outer direction, leading to a passivated Co-enriched surface layer.

\section{CONCLUSIONS}

In summary, we have presented a complete structural and magnetic characterization of Codoped $\mathrm{ZnO}$ nanoparticles synthesized via microwave-assisted hydrothermal route. All the results obtained in the structural characterization by the conjugation of different techniques confirm that the Co ions in the nanoparticles stay in character substitutional to the $\mathrm{Zn}$ ions in the $\mathrm{w}$ - ZnO lattice with oxidation state +2 . There was no indication of metallic Co or other secondary foreign phases. Electron microscopy results and state-of-art elemental distribution analysis performed via EELS reveal that the Co ions are mainly located near/at the surface of the $\mathrm{w}-\mathrm{ZnO}$ nanoparticles. The Corich $\mathrm{ZnO}$ surface is set passivated. The magnetic data present a combination of a diamagnetic $\mathrm{ZnO}$ 
matrix component associated with a ferromagnetic and a paramagnetic phases. The ferromagnetic phase is observed for the undoped $\mathrm{ZnO}$ sample; for the Co-doped $\mathrm{ZnO}$ samples, the ferromagnetic phase decreases as the Co content increases. At the light of the DFT results, we conclude that the observed RTFM is mainly associated with a surface magnetism and that a Co ferromagnetic order would be only possible at very low Co concentration. These results shine bright light on the understanding of the nature of the often observed RTFM in the Co-doped $w$-ZnO system.

The Co concentration in the studied samples measured by EDS ( $x_{\mathrm{E}}$ ) and the one obtained through the magnetic susceptibility $\left(x_{\mathrm{P}}\right)$ are in very good agreement with nominal concentration $\left(x_{\mathrm{N}}\right)$. However, a deep analyses of the paramagnetic phase shows that the Co ions are incorporated near/at the surface of the nanoparticles, corroborating the EELS results. Based on the experimental results and DFT calculations of the formation energy and the Co diffusion barrier energy through the nanoparticle, we conclude that the self-purification model is not an intrinsic and universal property of defects in nanostructures, and sketched a kinetic-thermodynamic model of the growth and Codoping process of the $\mathrm{ZnO}$ nanoparticles. The results presented in this report give a valuable contribution to the knowledge of the synthesis of doped nanoparticles for potential applications in different technological areas. It is also illustrated how the study of the magnetic properties, besides its natural importance, can give us very useful information about the doping elemental distribution at nanoscale.

\section{ACKNOWLEDGEMENTS}

Support from agencies FAPEMIG (PPM-00533-16; APQ-00273-14; RED-00010-14), CNPq (470069/2013-9; 448723/2014-0; 308162/2015-3, 306065/2015-0), FAPESP (2013/07909-4; 2015/16191-5) and CAPES (PNPD-2011) are gratefully acknowledged. We also thank CNPq (WAAM, MIBB and ACD) and CAPES (NCM, AOZ) for research fellowships. We thank Red Española de Supercomputación (Proyect ID: QCM-2014-1-0036) and CENAPAD/SP (Brazil) for computing facilities. The authors also acknowledge Prof. Dr. F. Iikawa and Profa. Dra. M. J. S. Brasil of the Universidade de Campinas (UNICAMP) for the Raman measurements and Dr. 
Jefferson Bettini of the Brazilian Nanotechnology National Laboratory (LNNano) for the EELS analysis.

\section{REFERENCES}

1. A. Teke, U. Ozgur, S. Dogan, X. Gu, H. Morkoc, B. Nemeth, J. Nause and H. O. Everitt, Physical Review B, 2004, 70, 195207.

2. G. C. Deng, A. L. Ding, W. X. Cheng, X. S. Zheng and P. S. Qiu, Solid State Communications, 2005, 134, 283-286.

3. J. H. Lee, K. H. Ko and B. O. Park, Journal of Crystal Growth, 2003, 247, 119-125.

4. R. Ullah and J. Dutta, Journal of Hazardous Materials, 2008, 156, 194-200.

5. Y. T. Kim, J. Park, S. Kim, D. W. Park and J. Choi, Electrochimica Acta, 2012, 78, 417-421.

6. M. Ohtaki, Journal of the Ceramic Society of Japan, 2011, 119, 770-775.

7. B. Kumar and S. W. Kim, Nano Energy, 2012, 1, 342-355.

8. D. T. Phan and G. S. Chung, Sensors and Actuators B-Chemical, 2012, 161, 341-348.

9. H. M. Xiong, Advanced Materials, 2013, 25, 5329-5335.

10. S. B. Rana and R. P. P. Singh, Journal of Materials Science-Materials in Electronics, 2016, 27, 9346-9355.

11. D. Y. Inamdar, A. K. Pathak, I. Dubenko, N. Ali and S. Mahamuni, Journal of Physical Chemistry C, 2011, 115, 23671-23676.

12. S. Kumar, S. Chatterjee, K. K. Chattopadhyay and A. K. Ghosh, Journal of Physical Chemistry C, 2012, 116, 16700-16708.

13. S. B. Rana, Journal of Materials Science-Materials in Electronics, 2017, 28, 13787-13796.

14. I. Zutic, J. Fabian and S. Das Sarma, Reviews of Modern Physics, 2004, 76, 323-410.

15. T. Dietl, H. Ohno, F. Matsukura, J. Cibert and D. Ferrand, Science, 2000, 287, 1019-1022.

16. H. B. de Carvalho, M. P. F. de Godoy, R. W. D. Paes, M. Mir, A. Ortiz de Zevallos, F. Iikawa, M. J. S. P. Brasil, V. A. Chitta, W. B. Ferraz, M. A. Boselli and A. C. S. Sabioni, J Appl. Phys., 2010, 108, 033914.

17. S. Kolesnik, B. Dabrowski and J. Mais, JAppl. Phys., 2004, 95, 2582-2586.

18. M. P. F. de Godoy, A. Mesquita, W. Avansi, P. P. Neves, V. A. Chitta, W. B. Ferraz, M. A. Boselli, A. C. S. Sabioni and H. B. de Carvalho, Journal of Alloys and Compounds, 2013, 555, 315-319.

19. V. M. de Almeida, A. Mesquita, A. O. de Zevallos, N. C. Mamani, P. P. Neves, X. Gratens, V. A. Chitta, W. B. Ferraz, A. C. Doriguetto, A. C. S. Sabioni and H. B. de Carvalho, Journal of Alloys and Compounds, 2016, 655, 406-414.

20. N. C. Mamani, R. T. da Silva, A. O. de Zevallos, A. A. C. Cotta, W. A. D. Macedo, M. S. Li, M. I. B. Bernardi, A. C. Doriguetto and H. B. de Carvalho, Journal of Alloys and Compounds, 2017, 695, 2682-2688.

21. G. Rahman, V. M. Garcia-Suarez and S. C. Hong, Physical Review B, 2008, 78, 184404.

22. G. Rahman, N. U. Din, V. M. Garcia-Suarez and E. Kan, Physical Review B, 2013, 87, 205205.

23. R. P. P. Singh, I. S. Hudiara, S. Panday and S. B. Rana, Journal of Superconductivity and Novel Magnetism, 2016, 29, 819-827. 
24. J. D. Bryan and D. R. Gamelin, Progress in Inorganic Chemistry, Vol 54, 2005, 54, 47-126.

25. A. L. Efros, E. I. Rashba and M. Rosen, Physical Review Letters, 2001, 87, 206601.

26. D. J. Norris, A. L. Efros and S. C. Erwin, Science, 2008, 319, 1776-1779.

27. J. F. Suyver, S. F. Wuister, J. J. Kelly and A. Meijerink, Physical Chemistry Chemical Physics, 2000, 2, 5445-5448.

28. M. I. B. Bernardi, A. Mesquita, F. Beron, K. R. Pirota, A. O. de Zevallos, A. C. Doriguetto and H. B. de Carvalho, Physical Chemistry Chemical Physics, 2015, 17, 3072-3080.

29. A. C. Larson and R. B. V. Dreele, Journal, 1994.

30. B. H. Toby, J. Appl. Crystallogr., 2001, 34, 210-213.

31. A. Michalowicz, Moscovici, J., Muller-Bouvet, D., Provost, K., Journal of Physics: Conference Series, 2009, 190, 012034.

32. A. L. Ankudinov, B. Ravel, J. J. Rehr and S. D. Conradson, Physical Review B, 1998, 58, 7565-7576.

33. P. Hohenberg and W. Kohn, Physical Review B, 1964, 136, B864- B871.

34. W. Kohn and L. J. Sham, Physical Review, 1965, 140, A1133-A1138.

35. J. P. Perdew and A. Zunger, Physical Review B, 1981, 23, 5048-5079.

36. A. L. Schoenhalz and G. M. Dalpian, Physical Chemistry Chemical Physics, 2013, 15, 15863-15868.

37. A. L. Schoenhalz, J. T. Arantes, A. Fazzio and G. M. Dalpian, Applied Physics Letters, 2009, 94, 162503.

38. J. M. Soler, E. Artacho, J. D. Gale, A. Garcia, J. Junquera, P. Ordejon and D. Sanchez-Portal, Journal of Physics-Condensed Matter, 2002, 14, 2745-2779.

39. N. Troullier and J. L. Martins, Physical Review B, 1991, 43, 1993-2006.

40. S. C. Abrahams and Bernstei.Jl, Acta Crystallogr. Sect. B Struct. Sci., 1969, B 25, 12331236.

41. R. Shannon, Acta Crystallographica Section A, 1976, 32, 751-767.

42. D. A. Schwartz, N. S. Norberg, Q. P. Nguyen, J. M. Parker and D. R. Gamelin, Journal of the American Chemical Society, 2003, 125, 13205-13218.

43. X. Gratens, E. ter Haar, V. Bindilatti, N. Oliveira, Y. Shapira, M. Liu, Z. Golacki, S. Charar and A. Errebbahi, Journal of Physics-Condensed Matter, 2000, 12, 3711-3718.

44. M. Pal, U. Pal, J. Jimenez and F. Perez-Rodriguez, Nanoscale Research Letters, 2012, 7, 112.

45. M. Scepanovic, S. Askrabic, V. Berec, A. Golubovic, Z. Dohcevic-Mitrovic, A. Kremenovic and Z. V. Popovic, Acta Physica Polonica A, 2009, 115, 771-774.

46. X. F. Wang, F. Q. Song, Q. Chen, T. Y. Wang, J. L. Wang, P. Liu, M. R. Shen, J. G. Wan, G. H. Wang and J. B. Xu, Journal of the American Chemical Society, 2010, 132, 6492-6497.

47. T. Sugimoto, Monodispersed Particles, Elsevier, Amsterdam, 2001.

48. L. Guo, S. H. Yang, C. L. Yang, P. Yu, J. N. Wang, W. K. Ge and G. K. L. Wong, Chemistry of Materials, 2000, 12, 2268-2274.

49. R. Viswanatha and D. D. Sarma, Chemistry-a European Journal, 2006, 12, 180-186.

50. N. S. Pesika, Z. S. Hu, K. J. Stebe and P. C. Searson, Journal of Physical Chemistry B, 2002, 106, 6985-6990.

51. R. L. He, R. K. Hocking and T. Tsuzuki, Materials Chemistry and Physics, 2012, 132, 10351040 . 
52. J. Kaur and S. Singhal, Ceramics International, 2014, 40, 7417-7424.

53. K. C. Barick, S. Singh, M. Aslam and D. Bahadur, Microporous and Mesoporous Materials, 2010, 134, 195-202.

54. R. Cusco, E. Alarcon-Llado, J. Ibanez, L. Artus, J. Jimenez, B. Wang and M. J. Callahan, Physical Review B, 2007, 75, 165202.

55. $\quad$ F. Friedrich and N. H. Nickel, Applied Physics Letters, 2007, 91, 111903.

56. F. Reuss, C. Kirchner, T. Gruber, R. Kling, S. Maschek, W. Limmer, A. Waag and P. Ziemann, Journal of Applied Physics, 2004, 95, 3385-3390.

57. Z. Q. Chen, A. Kawasuso, Y. Xu, H. Naramoto, X. L. Yuan, T. Sekiguchi, R. Suzuki and T. Ohdaira, Journal of Applied Physics, 2005, 97, 013528.

58. M. Schumm, M. Koerdel, S. Muller, H. Zutz, C. Ronning, J. Stehr, D. M. Hofmann and J. Geurts, New Journal of Physics, 2008, 10, 043004.

59. G. J. Huang, J. B. Wang, X. L. Zhong, G. C. Zhou and H. L. Yan, Journal of Materials Science, 2007, 42, 6464-6468.

60. L. H. Hoang, N. T. M. Hien, N. H. Hai, P. V. Hai, N. T. Khoi and I. S. Yang, Journal of Raman Spectroscopy, 2009, 40, 1535-1538.

61. J. W. Tringe, H. W. Levie, S. K. McCall, N. E. Teslich, M. A. Wall, C. A. Orme and M. J. Matthews, Applied Physics a-Materials Science \& Processing, 2012, 109, 15-23.

62. J. Zuo, C. Y. Xu, L. H. Zhang, B. K. Xu and R. Wu, Journal of Raman Spectroscopy, 2001, 32, 979-981.

63. M. Scepanovic, M. Grujic-Brojcin, K. Vojisavljevic, S. Bernik and T. Sreckovic, Journal of Raman Spectroscopy, 2010, 41, 914-921.

64. S. Ghose, T. Rakshit, R. Ranganathan and D. Jana, Rsc Advances, 2015, 5, 99766-99774.

65. R. H. Callender, S. S. Sussman, M. Selders and R. K. Chang, Phys. Rev. B, 1973, 7, 37883798.

66. P. J. Colwell and M. V. Klein, Solid State Communications, 1970, 8, 2095-2100.

67. J. Pellicer-Porres, A. Segura, J. F. Sanchez-Royo, J. A. Sans, J. P. Itie, A. M. Flank, P. Lagarde and A. Polian, Superlattices Microstruct., 2007, 42, 251-254.

68. L. R. Valério, N. C. Maman, A. O. de Zevallos, A. Mesquita, M. I. B. Bernardi, A. C. Doriguetto and H. B. de Carvalho, RSC Advances, 2017, 7, 20611-20619.

69. X. Gratens, V. Bindilatti, N. F. Oliveira, Y. Shapira, S. Foner, Z. Golacki and T. E. Haas, Physical Review B, 2004, 69, 125209.

70. M. Bouloudenine, N. Viart, S. Colis, J. Kortus and A. Dinia, Appl. Phys. Lett., 2005, 87.

71. T. E. de Souza, A. Mesquita, A. O. de Zevallos, F. Beron, K. R. Pirota, P. P. Neves, A. C. Doriguetto and H. B. de Carvalho, Journal of Physical Chemistry C, 2013, 117, 1325213260.

72. C. J. Chen, M. Qu, W. Hu, X. Zhang, F. Lin, H. B. Hu, K. J. Ma and W. Giriat, J. Appl. Phys., 1991, 69, 6114-6116.

73. D. Heiman, Y. Shapira, S. Foner, B. Khazai, R. Kershaw, K. Dwight and A. Wold, Physical Review B, 1984, 29, 5634-5640.

74. A. Sundaresan, R. Bhargavi, N. Rangarajan, U. Siddesh and C. N. R. Rao, Physical Review $B, 2006,74,161306$.

75. S. Banerjee, M. Mandal, N. Gayathri and M. Sardar, Applied Physics Letters, 2007, 91, 182501.

76. J. M. D. Coey, Solid State Sciences, 2005, 7, 660-667. 
77. G. Z. Xing, D. D. Wang, J. B. Yi, L. L. Yang, M. Gao, M. He, J. H. Yang, J. Ding, T. C. Sum and T. Wu, Applied Physics Letters, 2010, 96, 112511.

78. D. Q. Gao, Z. H. Zhang, J. L. Fu, Y. Xu, J. Qi and D. S. Xue, Journal of Applied Physics, 2009, 105, 113928.

79. X. Y. Xu, C. X. Xu, J. Dai, J. G. Hu, F. J. Li and S. Zhang, Journal of Physical Chemistry C, 2012, 116, 8813-8818.

80. N. H. Hong, J. Sakai and V. Brize, Journal of Physics-Condensed Matter, 2007, 19, 036219.

81. J. B. Yi, C. C. Lim, G. Z. Xing, H. M. Fan, L. H. Van, S. L. Huang, K. S. Yang, X. L. Huang, X. B. Qin, B. Y. Wang, T. Wu, L. Wang, H. T. Zhang, X. Y. Gao, T. Liu, A. T. S. Wee, Y. P. Feng and J. Ding, Physical Review Letters, 2010, 104, 137201.

82. M. Khalid, M. Ziese, A. Setzer, P. Esquinazi, M. Lorenz, H. Hochmuth, M. Grundmann, D. Spemann, T. Butz, G. Brauer, W. Anwand, G. Fischer, W. A. Adeagbo, W. Hergert and A. Ernst, Physical Review B, 2009, 80, 035331.

83. X. B. Chen, G. S. Li, Y. G. Su, X. Q. Qiu, L. P. Li and Z. G. Zou, Nanotechnology, 2009, 20, 115606.

84. A. Y. Yermakov, G. S. Zakharova, M. A. Uimin, M. V. Kuznetsov, L. S. Molochnikov, S. F. Konev, A. S. Konev, A. S. Minin, V. V. Mesilov, V. R. Galakhov, A. S. Volegov, A. V. Korolyov, A. F. Gubkin, A. M. Murzakayev, A. D. Svyazhin and K. V. Melanin, Journal of Physical Chemistry C, 2016, 120, 28857-28866.

85. J. M. D. Coey, M. Venkatesan and P. Stamenov, Journal of Physics-Condensed Matter, 2016, 28, 485001.

86. G. S. Chang, J. Forrest, E. Z. Kurmaev, A. N. Morozovska, M. D. Glinchuk, J. A. McLeod, A. Moewes, T. P. Surkova and N. H. Hong, Physical Review B, 2012, 85, 165319.

87. P. Sati, R. Hayn, R. Kuzian, S. Regnier, S. Schafer, A. Stepanov, C. Morhain, C. Deparis, M. Laugt, M. Goiran and Z. Golacki, Phys. Rev. Lett., 2006, 96, 017203.

88. N. Jedrecy, H. J. von Bardeleben, Y. Zheng and J. L. Cantin, Phys. Rev. B, 2004, 69, 041308.

89. S. J. Han, B. Y. Lee, J. S. Ku, Y. B. Kim and Y. H. Jeong, J. Magn. Magn. Mater., 2004, 272, 2008-2009.

90. D. Heiman, Y. Shapira and S. Foner, Solid State Communications, 1983, 45, 899-902.

91. M. Nawrocki, R. Planel, F. Mollot and M. J. Kozielski, Physica Status Solidi B-Basic Research, 1984, 123, 99-103.

92. S. Yin, M. X. Xu, L. Yang, J. F. Liu, H. Rosner, H. Hahn, H. Gleiter, D. Schild, S. Doyle, T. Liu, T. D. Hu, E. Takayama-Muromachi and J. Z. Jiang, Phys. Rev. B, 2006, 73, 224408.

93. L. B. Duan, W. G. Chu, J. Yu, Y. C. Wang, L. N. Zhang, G. Y. Liu, J. K. Liang and G. H. Rao, J. Magn. Magn. Mater., 2008, 320, 1573-1581.

94. Y. Shapira and V. Bindilatti, Journal of Applied Physics, 2002, 92, 4155-4185.

95. J. A. Gaj, R. Planel and G. Fishman, Solid State Communications, 1979, 29, 435-438.

96. The cluster tables are given in the EPAPS document at the homepage http://ftp.aip.org/epaps/app_phys_rev/E-JAPIAU-92-110220/.

97. G. M. Dalpian and J. R. Chelikowsky, Physical Review Letters, 2006, 96, 226802.

98. S. C. Erwin, L. J. Zu, M. I. Haftel, A. L. Efros, T. A. Kennedy and D. J. Norris, Nature, 2005, 436, 91-94.

99. D. A. Chen, R. Viswanatha, G. L. Ong, R. G. Xie, M. Balasubramaninan and X. G. Peng, Journal of the American Chemical Society, 2009, 131, 9333-9339.

100. J. B. Li, S. H. Wei, S. S. Li and J. B. Xia, Physical Review B, 2008, 77, 113304. 
101. A. Mesquita, F. P. Rhodes, R. T. da Silva, P. P. Neves, A. O. de Zevallos, M. R. B. Andreeta, M. M. de Lima, Jr., A. Cantarero, I. S. da Silva, M. A. Boselli, X. Gratens, V. A. Chitta, A. C. Doriguetto, W. B. Ferraz, A. C. S. Sabioni and H. B. de Carvalho, Journal of Alloys and Compounds, 2015, 637, 407-417.

102. G. H. Vineyard, Journal of Physics and Chemistry of Solids, 1957, 3, 121-127.

103. A. Janotti and C. G. Van de Walle, Physical Review B, 2007, 76, 165202. 